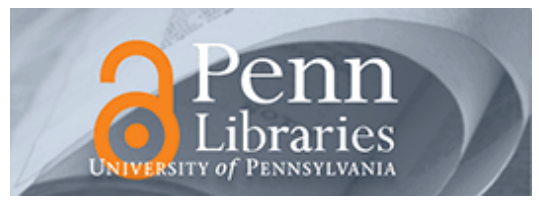

University of Pennsylvania

ScholarlyCommons

Finance Papers

Wharton Faculty Research

2006

\title{
A Consumption-Based Explanation of Expected Stock Returns
}

Motohiro Yogo

University of Pennsylvania

Follow this and additional works at: https://repository.upenn.edu/fnce_papers

Part of the Finance Commons, and the Finance and Financial Management Commons

\section{Recommended Citation}

Yogo, M. (2006). A Consumption-Based Explanation of Expected Stock Returns. The Journal of Finance, 61 (2), 539-580. http://dx.doi.org/10.1111/j.1540-6261.2006.00848.x

This paper is posted at ScholarlyCommons. https://repository.upenn.edu/fnce_papers/274

For more information, please contact repository@pobox.upenn.edu. 


\title{
A Consumption-Based Explanation of Expected Stock Returns
}

\author{
Abstract \\ When utility is nonseparable in nondurable and durable consumption and the elasticity of substitution \\ between the two consumption goods is sufficiently high, marginal utility rises when durable consumption \\ falls. The model explains both the cross-sectional variation in expected stock returns and the time \\ variation in the equity premium. Small stocks and value stocks deliver relatively low returns during \\ recessions, when durable consumption falls, which explains their high average returns relative to big \\ stocks and growth stocks. Stock returns are unexpectedly low at business cycle troughs, when durable \\ consumption falls sharply, which explains the countercyclical variation in the equity premium. \\ Disciplines \\ Finance | Finance and Financial Management
}




\title{
A Consumption-Based Explanation of Expected Stock Returns
}

\author{
Motohiro Yogo* \\ Job Market Paper
}

\begin{abstract}
When utility is non-separable in nondurable and durable consumption and the elasticity of substitution between the goods is high, marginal utility rises when durable consumption falls. The model explains both the cross-sectional variation in expected stock returns and the time variation in the equity premium. Small stocks and value stocks deliver relatively low returns during recessions when durable consumption falls, which explains their high average returns relative to big stocks and growth stocks. Stock returns are unexpectedly low at business-cycle troughs when durable consumption falls sharply, which explains the counter-cyclical variation in the equity premium. (JEL E21, E32, E44, G12)
\end{abstract}

First draft: March 7, 2003

This draft: October 29, 2003

*Department of Economics, Harvard University, Cambridge, MA 02138 (e-mail: yogo@fas.harvard.edu). An earlier draft was circulated with the title "A Consumption-Based Explanation of the Cross Section of Expected Stock Returns." I am grateful for comments by John Campbell, John Cochrane, Borja Larrain, Jonathan Parker, Monika Piazzesi, Tuomo Vuolteenaho, and seminar participants at Harvard. This paper is based upon work supported under a National Science Foundation Graduate Research Fellowship. 
Explaining the variation in expected returns across stocks and the variation in the equity premium through time as a tradeoff between risk and return is a challenge for financial economists. In his review article on market efficiency, Fama (1991, p. 1610) concludes

In the end, I think we can hope for a coherent story that (1) relates the crosssection properties of expected returns to the variation of expected returns through time, and (2) relates the behavior of expected returns to the real economy in a rather detailed way. Or we can hope to convince ourselves that no such story is possible.

This paper proposes a "coherent story" that satisfies both criteria.

A well-known empirical fact in finance is the high average returns of small stocks relative to big stocks (i.e. low relative to high market equity stocks) and value stocks relative to growth stocks (i.e. high relative to low book-to-market equity stocks). The evidence suggests that there are size and value premia in the cross section of expected stock returns. In an equilibrium asset pricing model, cross-sectional variation in expected returns must be explained by cross-sectional variation in risk. The Capital Asset Pricing Model (CAPM), where risk is measured by market beta, fails to explain the size and value premia (see Fama and French (1992) and references therein). The Consumption CAPM (CCAPM), where risk is measured by nondurable consumption beta, also fails to explain the cross section of expected stock returns (Mankiw and Shapiro 1986, Breeden, Gibbons, and Litzenberger 1989).

Another well-known empirical fact is the predictability of stock returns by variables that are informative about the business cycle (see Keim and Stambaugh (1986), Campbell (1987), Campbell and Shiller (1988b), and Fama and French $(1988,1989))$. The evidence suggests that the equity premium is time varying, that it is higher at business-cycle troughs than at peaks. In an equilibrium asset pricing model, time variation in the equity premium must be explained by time variation in the price or quantity of risk. Although there is some evidence for time variation in risk, it cannot be reconciled with the evidence for expected returns in a way that offers a consistent description of the time-varying tradeoff between risk and return (see Harvey (1989) for evidence on the CAPM and Kandel and Stambaugh (1990) for the 


\section{CCAPM).}

This paper proposes a simple consumption-based explanation of both the cross-sectional variation in expected stock returns and the counter-cyclical variation in the equity premium. I use a representative household model, where intraperiod utility is a constant elasticity of substitution (CES) function of nondurable and durable consumption. It nests the CCAPM as a special case when utility is separable in the two consumption goods.

In the language of macroeconomics, the main findings can be summarized as follows. When the elasticity of substitution between nondurable and durable consumption is high, the marginal utility of consumption rises when durable consumption falls. First, small stocks and value stocks deliver low returns when marginal utility rises, that is during recessions when durable consumption falls. Investors must therefore be rewarded with high expected returns to hold these risky stocks. Second, stocks deliver unexpectedly low returns when marginal utility rises sharply, that is at business-cycle troughs when durable consumption falls sharply relative to nondurable consumption. Investors must therefore be rewarded with high expected returns to hold stocks during recessions.

In the language of finance, the main findings can be summarized as follows. When utility is non-separable in nondurable and durable consumption, optimal portfolio allocation implies a two-factor model in nondurable and durable consumption growth. The risk price for durable consumption is positive, provided that the elasticity of substitution between the two goods is high. First, small stocks and value stocks have higher durable consumption betas than big stocks and growth stocks. Simply put, the returns on small stocks and value stocks are more pro-cyclical, explaining their high average returns. Second, the covariance of stock returns with durable consumption growth is higher at business-cycle troughs than at peaks. The equity premium is therefore counter-cyclical because the quantity of risk, measured by the conditional covariance of returns with durable consumption growth, is counter-cyclical.

Previous papers that have tested the representative household model with durable consumption include Dunn and Singleton (1986), Eichenbaum and Hansen (1990), and Ogaki and Reinhart (1998). These papers test the conditional moment restrictions implied by the model using T-bill returns and instruments. This paper instead tests the unconditional moment restrictions using a large cross section of stock returns, and the conditional moment 
restrictions using stock returns and instruments that predict returns. Because both nondurable and durable consumption are smooth, the model requires large risk aversion to fit the high level and volatility of expected stock returns. This paper shows that the model can successfully explain the cross-sectional and time variation in expected stock returns, conditional on an "equity premium puzzle" (Mehra and Prescott 1985).

In related work, Pakǒs (2003) considers a representative household model with nonhomothetic utility in nondurable and durable consumption goods. He focuses on the Leontief model, where the elasticity of substitution between the two goods is zero. Since the consumption of durables relative to nondurables is pro-cyclical, a low elasticity of substitution between the goods implies pro-cyclical marginal utility. The Leontief model therefore cannot explain the value premium (since value stocks are more pro-cyclical than growth stocks) or the counter-cyclical variation in the equity premium. In contrast, I estimate a high elasticity of substitution between the goods, implying counter-cyclical marginal utility.

The rest of the paper is organized as follows. Section 1 reviews the household's consumption and portfolio choice problem in the presence of durable consumption goods. In Section 2, I linearize the unconditional Euler equation to obtain a two-factor model in nondurable and durable consumption growth. I show that the linear factor model can be estimated by Generalized Method of Moments (GMM). In Section 3, I linearize the conditional Euler equation to obtain a conditional factor model in nondurable and durable consumption growth. I show that its conditional moments can be estimated by an instrumental variables methodology (Campbell 1987, Harvey 1989).

Section 4 provides a description of the consumption data used in the empirical work. The service flow for "durable goods" (as defined in the national accounts) is more cyclical than the service flow for "nondurable goods" and "services". The high cyclicality of the service flow, rather than durability of the good, is the key ingredient in explaining the known facts about expected stock returns.

Section 5 reports the cross-sectional tests. I find that the durable consumption model explains the variation in average returns across the 25 Fama-French (1993) portfolios better than the Fama-French three-factor model; the $R^{2}$ for these models are $77 \%$ and $66 \%$, respectively. The durable consumption model is not rejected by the test that the pricing errors are 
jointly zero, while the CAPM, the three-factor model, and the CCAPM are all rejected. The model also explains returns on portfolios sorted by book-to-market equity within industry and portfolios sorted by risk (i.e. pre-formation betas).

Section 6 reports the time series tests of the model. I estimate the conditional Euler equation by GMM, using excess stock returns and instruments. The test of overidentifying restrictions fails to reject the model. The CCAPM, which is a restriction that utility be separable in nondurable and durable consumption, is strongly rejected (Hansen and Singleton 1982). To connect these results to the predictability of stock returns, I jointly estimate the conditional mean and variance of stock returns and its conditional covariance with nondurable and durable consumption growth. I find that much of the counter-cyclical variation in the equity premium is driven by counter-cyclical variation in the conditional covariance of returns with durable (rather than nondurable) consumption growth, explaining the failure of the CCAPM.

The large risk aversion required to explain stock returns not only implies a high riskfree rate (Weil 1989), but high volatility in the riskfree rate due to the high persistence of durable consumption growth. In Section 7, I show that this "riskfree rate puzzle" can be resolved by separating risk aversion from the elasticity of intertemporal substitution (EIS) with more general preferences.

Section 8 offers some conclusions. Supplementary derivations and results are contained in a separate appendix (Yogo 2003), referenced throughout the text.

\section{Household Optimization with Durable Consumption Goods}

\section{$1.1 \quad$ Euler Equations}

Consider the canonical consumption and portfolio choice problem of a household. In each period $t$, the household purchases $C_{t}$ units of nondurable consumption goods and $E_{t}$ units of durable consumption goods. $P_{t}$ is the price of durable goods in units of nondurable goods. Nondurable goods are entirely consumed in the period of purchase, whereas durable goods 
provide service flows for more than one period. The household's stock of durable goods $D_{t}$ is related to its expenditures by the law of motion

$$
D_{t}=(1-\delta) D_{t-1}+E_{t},
$$

where $\delta \in(0,1)$ is the depreciation rate.

There are $N+1$ tradeable assets in the economy, indexed by $i=0,1, \ldots, N$. In period $t-1$, the household invests $B_{i, t-1}$ units of wealth $W_{t-1}$ in asset $i$, which realizes the gross rate of return $R_{i t}$ in period $t$. Given the initial level of wealth, $W_{0}$, and the initial stock of durable goods, $D_{-1}$, the household chooses the sequence $\left\{C_{t}, E_{t}, B_{0 t}, \ldots, B_{N t}\right\}_{t=0}^{\infty}$ to maximize

$$
\mathbf{E}_{0} \sum_{t=0}^{\infty} \beta^{t} u\left(C_{t}, D_{t}\right)
$$

subject to the intertemporal budget constraint

$$
\begin{aligned}
W_{t} & =\sum_{i=0}^{N} B_{i, t-1} R_{i t}, \\
\sum_{i=0}^{N} B_{i t} & =W_{t}-C_{t}-P_{t} E_{t} .
\end{aligned}
$$

$\beta>0$ is the household's subjective discount factor, and $u_{t}=u\left(C_{t}, D_{t}\right)$ is its period utility, which depends on the consumption of nondurable goods and the stock of durable goods.

Let $u_{C t}$ and $u_{D t}$ denote the marginal utility of $C_{t}$ and $D_{t}$, respectively. The household's first-order conditions and the envelope theorem imply the pair of Euler equations

$$
\begin{aligned}
u_{C, t-1} & =\mathbf{E}_{t-1}\left[\beta u_{C t} R_{i t}\right], \\
u_{D, t-1} & =\mathbf{E}_{t-1}\left[\beta u_{C t}\left(P_{t-1} R_{i t}-(1-\delta) P_{t}\right)\right] .
\end{aligned}
$$

Define the stochastic discount factor (SDF) as $M_{t}=\beta u_{C t} / u_{C, t-1}$. Equations (5) and (6) together imply an intratemporal first-order condition (FOC) of the form

$$
\frac{u_{D, t-1}}{u_{C, t-1}}=P_{t-1}-(1-\delta) \mathbf{E}_{t-1}\left[M_{t} P_{t}\right]=Q_{t-1} .
$$

Since a unit of the durable consumption good costs $P_{t-1}$ today and can be sold for $(1-\delta) P_{t}$ tomorrow, after depreciation, $Q_{t-1}$ has a natural interpretation as the user cost of the service flow for the durable good. 


\section{$1.2 \quad$ Asset Pricing}

Equation (5) can be written as

$$
\mathbf{E}_{t-1}\left[M_{t} R_{i t}\right]=1
$$

The excess return on asset $i$ then satisfies

$$
\mathbf{E}_{t-1}\left[M_{t}\left(R_{i t}-R_{0 t}\right)\right]=0
$$

Equation (8) is the basis for consumption-based asset pricing. The marginal utility of consumption is the appropriate measure of risk for an investor who cares about consumption. Assets that deliver low returns when marginal utility is high must have high expected returns to reward the investor for bearing risk. On the other hand, assets that deliver high returns when marginal utility is high provides a good hedge for consumption risk and must consequently have low expected returns.

Equation (8) was derived here in the context of a household optimization problem, but it holds more generally by a well-known existence theorem. In the absence of arbitrage, there exists a strictly positive SDF, $M_{t}$, which satisfies equation (8) for all tradable assets $i=0,1, \ldots, N$ (see Cochrane (2001, Chapter 4.2)). Various asset pricing models correspond to particular forms of the SDF. In the consumption-based model, the SDF is the marginal rate of substitution in consumption.

\subsection{CES Utility}

I now specify a particular form of utility that is used in the empirical work. The period utility takes the form

$$
u(C, D)=\frac{v(C, D)^{1-\gamma}}{1-\gamma},
$$

where $\gamma>0$ is the coefficient of relative risk aversion with respect to intraperiod utility flow. The intraperiod utility takes the CES form

$$
v(C, D)=\left[(1-\alpha) C^{\rho}+\alpha D^{\rho}\right]^{1 / \rho},
$$

where $\alpha \in(0,1)$ and $\rho \leq 1$. The elasticity of substitution between nondurable and durable consumption goods is $1 /(1-\rho)$. Implicit in this specification is the assumption that the 
service flow for the durable good is linear in the stock of the durable good. I therefore use the words "stock" and "consumption" interchangeably in regard to durable goods, hopefully without confusion. The utility specification (10) and (11) has been used previously in related empirical work by Dunn and Singleton (1986) and Ogaki and Reinhart (1998). ${ }^{1}$

When $\rho=1-\gamma$, the period utility is separable in nondurable and durable consumption,

$$
u(C, D)=(1-\alpha) \frac{C^{1-\gamma}}{1-\gamma}+\alpha \frac{D^{1-\gamma}}{1-\gamma} .
$$

The marginal utility of nondurable consumption takes the simple form $u_{C}=(1-\alpha) C^{-\gamma}$. The additively separable model is the leading case in macroeconomics and finance applications. It provides a useful reference point for the general model with CES intraperiod utility.

In the general case, the marginal utility of nondurable consumption is

$$
u_{C}=(1-\alpha) C^{-\gamma}\left[1+\alpha\left(\left(\frac{D}{C}\right)^{\rho}-1\right)\right]^{\frac{1-\gamma-\rho}{\rho}} .
$$

The marginal utility under the additively separable model is now multiplied by a function of the ratio of durable to nondurable consumption, $D / C$. Figure 1 illustrates the dependence of the marginal utility on $D / C$. For a given level of nondurable consumption, marginal utility decreases in $D / C$ if $\rho>1-\gamma$. Intuitively, low nondurable consumption can be offset by high durable consumption provided that the elasticity of substitution between the two goods is sufficiently high. On the other hand, relatively high durable consumption increases the marginal utility of nondurable consumption if the elasticity is low (i.e. $\rho<1-\gamma$ ). The additively separable model, where $\rho=1-\gamma$, is the knife-edge case when the marginal utility is independent of durable consumption.

The SDF for the durable consumption model is

$$
M_{t}=\beta\left(\frac{C_{t}}{C_{t-1}}\right)^{-\gamma}\left(\frac{1+\alpha\left[\left(D_{t} / C_{t}\right)^{\rho}-1\right]}{1+\alpha\left[\left(D_{t-1} / C_{t-1}\right)^{\rho}-1\right]}\right)^{\frac{1-\gamma-\rho}{\rho}} .
$$

The intratemporal FOC (7) takes the form

$$
\frac{\alpha}{1-\alpha}\left(\frac{D_{t-1}}{C_{t-1}}\right)^{\rho-1}=P_{t-1}-(1-\delta) \mathbf{E}_{t-1}\left[M_{t} P_{t}\right] .
$$

\footnotetext{
${ }^{1}$ Dunn and Singleton (1986) use Cobb-Douglas intraperiod utility, which corresponds to the special case $\rho=0$.
} 
In the empirical work, I assume that there is a representative household, so that assets can be priced by the SDF (14) using aggregate consumption data.

At the microeconomic level, there may be lumpiness in the adjustment of durable consumption, which can cause aggregate durable consumption to deviate from the optimal behavior implied by the frictionless model (see Grossman and Laroque (1990) and Caballero (1993)). As long as nondurable consumption still adjusts in a way that the Euler equation (5) holds, the slow adjustment of durable consumption does not pose a problem for asset pricing. ${ }^{2}$ However, the Euler equation for durable consumption (6), and consequently, the intratemporal FOC (15) may not hold due to frictions in the adjustment of durable consumption.

\subsection{A Log-Linear Approximation of the SDF}

I now introduce a linear approximation to the log of the SDF (14), which is convenient for transforming the asset pricing equation (8) into a linear factor model. Let lowercase letters denote the logs of the corresponding uppercase variables. Taking the log of both sides of (14) and approximating around the special case of Cobb-Douglas intraperiod utility (i.e. $\rho=0$ ),

$$
m_{t} \approx \log \beta-\gamma \Delta c_{t}+\alpha(1-\gamma-\rho)\left(\Delta d_{t}-\Delta c_{t}\right)
$$

The approximation is exact when $\rho=0$. Let $\bar{r}=-\log \beta, f_{t}=\left(\Delta c_{t}, \Delta d_{t}\right)^{\prime}$, and

$$
b=\left[\begin{array}{l}
b_{1} \\
b_{2}
\end{array}\right]=\left[\begin{array}{c}
\gamma+\alpha(1-\gamma-\rho) \\
-\alpha(1-\gamma-\rho)
\end{array}\right]
$$

Then equation (16) can be written more compactly as

$$
-m_{t} \approx \bar{r}+b^{\prime} f_{t}=\bar{r}+b_{1} \Delta c_{t}+b_{2} \Delta d_{t}
$$

$\bar{r}$ is the rate of time preference. $b_{1}$ and $b_{2}$ are the risk prices for the two risk factors, nondurable and durable consumption growth, respectively.

The risk price of durable consumption is positive when $\rho>1-\gamma$, that is when the elasticity of substitution between the two consumption goods is greater than the inverse of

\footnotetext{
${ }^{2}$ Ogaki and Reinhart (1998) make a similar argument to motivate their empirical methodology.
} 
risk aversion. Using quarterly data in the sample 1951:1-1983:4, Ogaki and Reinhart (1998, Table 2) estimate a $95 \%$ confidence interval of $[-0.03,0.27]$ for $\rho$. On the other hand, the literature on the equity premium puzzle suggests that $\gamma$ is large (see Campbell (2003) for a survey). Therefore, the assumption of additive separability is not supported by the data. Moreover, durable consumption is potentially an important risk factor that carries a large positive risk price.

An intuitive way to think about the risk prices for nondurable and durable consumption is the approximation

$$
\begin{aligned}
& b_{1}=(1-\alpha) \gamma+\alpha(1-\rho) \approx(1-\alpha) \gamma, \\
& b_{2}=\alpha \gamma-\alpha(1-\rho) \approx \alpha \gamma .
\end{aligned}
$$

The approximation holds in the empirically relevant case where $\rho \approx 0$ and $\gamma$ is large. The sum of the risk prices is total risk aversion $\gamma$. The fraction of risk attributed to nondurable consumption is $1-\alpha$, which is the budget share of nondurable consumption under CobbDouglas intraperiod utility.

\section{Linear Factor Models}

Taking the unconditional expectation of equation (9),

$$
\mathbf{E}\left[M_{t}\left(R_{i t}-R_{0 t}\right)\right]=0 .
$$

Suppose the SDF is linear in a vector $f_{t}$ of $F$ underlying factors, that is

$$
-\frac{M_{t}}{\mathbf{E}\left[M_{t}\right]}=k+b^{\prime} f_{t} .
$$

Let $\mu_{f}=\mathbf{E}\left[f_{t}\right], \Sigma_{f f}=\mathbf{E}\left[\left(f_{t}-\mu_{f}\right)\left(f_{t}-\mu_{f}\right)^{\prime}\right]$, and $\Sigma_{f i}=\mathbf{E}\left[\left(f_{t}-\mu_{f}\right)\left(R_{i t}-R_{0 t}\right)\right]$. Equation (19) can then be written as a linear factor model

$$
\mathbf{E}\left[R_{i t}-R_{0 t}\right]=b^{\prime} \Sigma_{f i} .
$$

This equation says that the premium on asset $i$ is the price of risk $b$ times its quantity of risk $\Sigma_{f i}$. 
Define the "beta" of asset $i$ as $\beta_{i}=\Sigma_{f f}^{-1} \Sigma_{f i}$, which can be interpreted as the coefficient vector in a multiple regression of $R_{i t}$ onto $f_{t}$. The linear factor model can be written as a beta pricing model

$$
\mathbf{E}\left[R_{i t}-R_{0 t}\right]=\lambda^{\prime} \beta_{i}
$$

where $\lambda=\Sigma_{f f} b$ is the factor risk premium.

\subsection{Fama-French Three-Factor Model}

In response to the failures of the CAPM and the CCAPM, Fama and French (1993) proposed an influential three-factor model. The three factors are excess returns on the market portfolio, returns on the SMB (Small Minus Big stocks) portfolio, and returns on the HML (High Minus Low book-to-market stocks) portfolio. The Fama-French three-factor model nests the static CAPM (Sharpe 1964, Lintner 1965) as a special case where the risk prices for SMB and HML are restricted to zero.

Although the model is an empirical success, it falls short of a satisfactory understanding of the underlying risk reflected in stock returns. "Without a theory that specifies the exact form of the state variables or common factors in returns, the choice of any particular version of the factors is somewhat arbitrary." (Fama and French 1993, p. 53) As emphasized by Cochrane (2001, Chapter 9), a satisfactory factor model must ultimately connect the factors to the marginal utility of consumption.

\subsection{Consumption-Based Model}

A nonlinear SDF, $M_{t}$, can be approximated by first-order log-linear approximation as

$$
\frac{M_{t}}{\mathbf{E}\left[M_{t}\right]} \approx 1+m_{t}-\mathbf{E}\left[m_{t}\right] .
$$

Using equation (18), the SDF (14) of the durable consumption model can be approximated as

$$
-\frac{M_{t}}{\mathbf{E}\left[M_{t}\right]} \approx k+b_{1} \Delta c_{t}+b_{2} \Delta d_{t}
$$

where $k=-1-b_{1} \mathbf{E}\left[\Delta c_{t}\right]-b_{2} \mathbf{E}\left[\Delta d_{t}\right]$. The corresponding linear factor model (20) is

$$
\mathbf{E}\left[R_{i t}-R_{0 t}\right]=b_{1} \operatorname{Cov}\left(\Delta c_{t}, R_{i t}-R_{0 t}\right)+b_{2} \operatorname{Cov}\left(\Delta d_{t}, R_{i t}-R_{0 t}\right)
$$


When $\rho=1-\gamma$ (i.e. additive separability), this equation reduces to

$$
\mathbf{E}\left[R_{i t}-R_{0 t}\right]=\gamma \operatorname{Cov}\left(\Delta c_{t}, R_{i t}-R_{0 t}\right)
$$

which is the familiar CCAPM (Rubinstein 1976, Breeden and Litzenberger 1978, Breeden 1979).

Equation (23) says that an asset with high nondurable consumption beta, $\operatorname{Cov}\left(\Delta c_{t}, R_{i t}-\right.$ $\left.R_{0 t}\right) / \operatorname{Var}\left(\Delta c_{t}\right)$, must have high expected returns. Likewise, an asset with high durable consumption beta, $\operatorname{Cov}\left(\Delta d_{t}, R_{i t}-R_{0 t}\right) / \operatorname{Var}\left(\Delta d_{t}\right)$, must have high expected returns when $b_{2}>0$. In equilibrium, differences in expected returns across assets must reflect differences in the quantity of risk across assets, measured by the covariance of returns with nondurable and durable consumption growth.

\subsection{An Approximation of the Intratemporal FOC}

Suppose the intraperiod utility is Cobb-Douglas (i.e. $\rho=0$ ). Substituting the linearized SDF (22) in the intratemporal FOC (15) and taking the expectation of both sides of the equation yields

$$
\begin{aligned}
\frac{b_{2}}{b_{1}-1} \mathbf{E}\left[\frac{C_{t-1}}{P_{t-1} D_{t-1}}\right]= & 1-a\left[\mathbf{E}\left[\frac{P_{t}}{P_{t-1}}\right]\right. \\
& \left.-b_{1} \operatorname{Cov}\left(\Delta c_{t}, \frac{P_{t}}{P_{t-1}}\right)-b_{2} \operatorname{Cov}\left(\Delta d_{t}, \frac{P_{t}}{P_{t-1}}\right)\right],
\end{aligned}
$$

where $a=(1-\delta) \mathbf{E}\left[M_{t}\right]$. Note that the parameters in this equation are the risk prices $b_{1}$ and $b_{2}$, rather than the preference parameters $\gamma, \rho$, and $\alpha$. Hence, the equation is a useful way of imposing the intratemporal FOC in estimating the linear factor model (23).

\subsection{GMM Estimation of Linear Factor Models}

Since the linear factor model is a set of moment restrictions on asset returns, GMM is a natural way to estimate and test the model. ${ }^{3}$ Since my focus is on consumption-based models, I base estimation on the covariance representation (20), rather than the beta representation

\footnotetext{
${ }^{3}$ See Cochrane (2001, Chapter 13) for a textbook treatment of GMM for linear factor models.
} 
(21) of the model. The coefficients $b$ of the covariance representation are immediately interpretable as preference parameters, unlike the coefficients $\lambda$ of the beta representation. In Yogo (2003, Section A), I relate the GMM estimator to an estimator of the risk prices based on a cross-sectional regression.

Define the parameter space $\Theta \subset \mathbb{R}^{2 F}$ with a generic element $\theta=\left(b^{\prime}, \mu_{f}^{\prime}\right)^{\prime}$. Let $R_{0 t}$, $R_{t}=\left(R_{1 t}, \ldots, R_{N t}\right)^{\prime}$, and $f_{t}$ be the time $t$ observation on the reference return, the vector of $N$ test asset returns, and the vector of $F$ factors, respectively. Stack the variables in a vector as $z_{t}=\left(R_{0 t}, R_{t}^{\prime}, f_{t}^{\prime}\right)^{\prime}$. Let $\iota$ be an $N \times 1$ vector of ones. Consider the $(N+F) \times 1$ moment function

$$
e\left(z_{t}, \theta\right)=\left[\begin{array}{c}
R_{t}-R_{0 t} \iota-\left(R_{t}-R_{0 t} \iota\right)\left(f_{t}-\mu_{f}\right)^{\prime} b \\
f_{t}-\mu_{f}
\end{array}\right] .
$$

The moment function satisfies the moment restriction $\mathbf{E}\left[e\left(z_{t}, \theta_{0}\right)\right]=0$, for some $\theta_{0} \in \Theta$, through equation (20). A necessary condition for identification is that $N \geq F$. A sufficient condition for identification is that the $F \times N$ matrix $\left[\Sigma_{f 1} \cdots \Sigma_{f N}\right]$ has rank $F$. This condition assures that $\theta_{0}$ is a unique solution to $\mathbf{E}\left[e\left(z_{t}, \theta\right)\right]=0$, so that the key identification condition for GMM is satisfied (see Wooldridge (1994, Theorem 7.1)). Intuitively, the factors cannot be perfectly correlated in order for the factor risk prices to be identified.

The overidentifying restrictions of the model can be tested by Hansen's (1982) J-test. The degree of overidentification is $N-F$, or $N-F+1$ for the durable consumption model when the intratemporal FOC (25) is imposed as an additional moment restriction. The $J$ test tests the null hypothesis that the pricing errors are jointly zero across the $N$ test assets. The test is conceptually similar to the GRS test (Gibbons, Ross, and Shanken 1989) since the test statistic is a quadratic form in the vector of pricing errors (see Cochrane (2001, Chapters 12-13)).

\section{Conditional Factor Model}

Let $R_{0 t}$ be a conditionally riskfree return, so that $R_{0 t}=1 / \mathbf{E}_{t-1}\left[M_{t}\right]$. (In practice, $R_{0 t}$ is a reference return over which excess returns are computed, such as the 90-day T-bill return.) Let lowercase letters denote the logs of the corresponding uppercase variables (e.g. 
$m_{t}=\log M_{t}$ and $\left.r_{0 t}=\log R_{0 t}\right)$. For assets $i=1, \ldots, N$, however, let $r_{i t}=\log R_{i t}-\log R_{0 t}$ be the log return in excess of the log riskfree rate. By a second-order log-linear approximation of equation (8) for the riskfree rate (see Campbell (2003)),

$$
r_{0 t}=-\mathbf{E}_{t-1} m_{t}-\frac{1}{2} \operatorname{Var}_{t-1}\left(m_{t}\right)
$$

Similarly, the excess return on asset $i$ can be approximated as

$$
\mathbf{E}_{t-1}\left[r_{i t}\right]+\frac{1}{2} \operatorname{Var}_{t-1}\left(r_{i t}\right)=-\operatorname{Cov}_{t-1}\left(m_{t}, r_{i t}\right)
$$

Suppose the $\log$ SDF is linear in a vector $f_{t}$ of $F$ underlying factors, that is

$$
-m_{t}=\bar{r}+b^{\prime} f_{t}=\bar{r}+\sum_{j=1}^{F} b_{j} f_{j t}
$$

Then equation (27) becomes

$$
r_{0 t}=\bar{r}+b^{\prime} \mathbf{E}_{t-1}\left[f_{t}\right]-\frac{1}{2} \operatorname{Var}_{t-1}\left(b^{\prime} f_{t}\right)
$$

and equation (28) can be written as a conditional factor model

$$
\mathbf{E}_{t-1}\left[r_{i t}\right]+\frac{1}{2} \operatorname{Var}_{t-1}\left(r_{i t}\right)=\sum_{j=1}^{F} b_{j} \operatorname{Cov}_{t-1}\left(f_{j t}, r_{i t}\right)
$$

This equation says that the premium on an asset is the price of risk $b_{j}$ times the quantity of risk $\operatorname{Cov}_{t-1}\left(f_{j t}, r_{i t}\right)$, summed over all factors $j=1, \ldots, F$.

\subsection{Consumption-Based Model}

Using the linear approximation to the $\log$ SDF (18), the riskfree rate for the durable consumption model is

$$
\begin{aligned}
r_{0 t}= & \bar{r}+b_{1} \mathbf{E}_{t-1}\left[\Delta c_{t}\right]+b_{2} \mathbf{E}_{t-1}\left[\Delta d_{t}\right] \\
& -\frac{b_{1}^{2}}{2} \operatorname{Var}_{t-1}\left(\Delta c_{t}\right)-\frac{b_{2}^{2}}{2} \operatorname{Var}_{t-1}\left(\Delta d_{t}\right)-b_{1} b_{2} \operatorname{Cov}_{t-1}\left(\Delta c_{t}, \Delta d_{t}\right) .
\end{aligned}
$$

The premium on asset $i$ is

$$
\mathbf{E}_{t-1}\left[r_{i t}\right]+\frac{1}{2} \operatorname{Var}_{t-1}\left(r_{i t}\right)=b_{1} \operatorname{Cov}_{t-1}\left(\Delta c_{t}, r_{i t}\right)+b_{2} \operatorname{Cov}_{t-1}\left(\Delta d_{t}, r_{i t}\right)
$$


When $\rho=1-\gamma$ (i.e. additive separability), this equation reduces to

$$
\mathbf{E}_{t-1}\left[r_{i t}\right]+\frac{1}{2} \operatorname{Var}_{t-1}\left(r_{i t}\right)=\gamma \operatorname{Cov}_{t-1}\left(\Delta c_{t}, r_{i t}\right)
$$

which is the familiar CCAPM.

Equation (32) says that the expected return on an asset is high when the covariance of its returns with nondurable consumption growth is high. Likewise, the expected return is high when the covariance of its returns with durable consumption growth is high, provided that $b_{2}>0$. In equilibrium, variation in expected returns through time must reflect variation in the quantity of risk through time, measured by the conditional covariance of returns with nondurable and durable consumption growth.

\subsection{Estimation of Conditional Moments Using Instruments}

I now describe a way to estimate the conditional moments of the conditional factor model (30), using a vector $x_{t-1}$ of $I$ instrumental variables known at time $t-1$. The essential idea behind the method is that the representative household's information set can always be conditioned down to the econometrician's information set. Equation (30) therefore holds even when the conditioning information is restricted to $x_{t-1}$. The methodology described here has been used previously in empirical work by Campbell (1987) and Harvey (1989).

Consider the linear regression model

$$
\begin{aligned}
r_{i t}=\Pi_{i}^{\prime} x_{t-1}+u_{i t} \quad(i=1, \ldots, N), \\
u_{i t} r_{i t}=\Gamma_{i}^{\prime} x_{t-1}+\epsilon_{i t} \quad(i=1, \ldots, N), \\
u_{i t} f_{j t}=\Upsilon_{i j}^{\prime} x_{t-1}+\eta_{i j t} \quad(i=1, \ldots, N ; j=1, \ldots, F) .
\end{aligned}
$$

Equations (34) and (35) model the conditional mean and variance of excess log returns, respectively. Equation (36) models the conditional covariance of excess log returns with the factors. The model (34)-(36) is exactly identified under the conditional moment restriction

$$
\mathbf{E}\left[\left(u_{i t}, \epsilon_{i t}, \eta_{i j t}\right)^{\prime} \mid x_{t-1}\right]=0 \quad \forall i, j .
$$


Define the matrices

$$
\begin{aligned}
& \Pi=\left[\Pi_{1} \cdots \Pi_{N}\right] \quad(I \times N), \\
& \Gamma=\left[\Gamma_{1} \cdots \Gamma_{N}\right] \quad(I \times N), \\
& \Upsilon_{j}=\left[\Upsilon_{1 j} \cdots \Upsilon_{N j}\right] \quad(I \times N) \text {, } \\
& \Upsilon=\left[\Upsilon_{1} \cdots \Upsilon_{F}\right] \quad(I \times N F) .
\end{aligned}
$$

The conditional factor model (30) implies NI linear restrictions of the form

$$
\Pi+\frac{1}{2} \Gamma=\sum_{j=1}^{F} b_{j} \Upsilon_{j} .
$$

Using this equation to substitute out $\Gamma_{i}$ in equation (35),

$$
u_{i t} r_{i t}=2\left(\sum_{j=1}^{F} b_{j} \Upsilon_{i j}-\Pi_{i}\right)^{\prime} x_{t-1}+\epsilon_{i t} .
$$

Assuming that the vector of risk prices $b$ is known, the model (34), (39), and (36) is overidentified by $N I$ degrees.

Define the parameter space $\Theta \subset \mathbb{R}^{(N+N F) I}$ with a generic element $\theta=\left(\operatorname{vec}(\Pi)^{\prime}, \operatorname{vec}(\Upsilon)^{\prime}\right)^{\prime}$. Let $r_{t}=\left(r_{1 t}, \ldots, r_{N t}\right)^{\prime}$ and $f_{t}$ be the time $t$ observation on the vector of $N$ excess log returns and the vector of $F$ factors, respectively. Stack the variables and the instruments in a vector as $z_{t}=\left(r_{t}^{\prime}, f_{t}^{\prime}, x_{t-1}\right)^{\prime}$. Consider the $(2 N+N F) I \times 1$ moment function

$$
e\left(z_{t}, \theta ; b\right)=\left[\begin{array}{c}
r_{t}-\Pi^{\prime} x_{t-1} \\
\operatorname{diag}\left(\left(r_{t}-\Pi^{\prime} x_{t-1}\right) r_{t}^{\prime}\right)-2\left(\sum_{j=1}^{F} b_{j} \Upsilon_{j}-\Pi\right)^{\prime} x_{t-1} \\
\operatorname{vec}\left(\left(r_{t}-\Pi^{\prime} x_{t-1}\right) f_{t}^{\prime}\right)-\Upsilon^{\prime} x_{t-1}
\end{array}\right] \otimes x_{t-1} .
$$

The moment function satisfies the moment restriction $\mathbf{E}\left[e\left(z_{t}, \theta_{0} ; b\right)\right]=0$, for some $\theta_{0} \in \Theta$, through the conditional moment restriction (37).

In practice, the vector of risk prices $b$ is not known. It can be estimated jointly with $\theta$ using the moment function (40), provided that $F \leq N I$. Instead, suppose there is a consistent estimator $\widehat{b}$. Then the GMM estimator for $\theta$ based on the moment function $e\left(z_{t}, \theta ; \widehat{b}\right)$ is consistent and has the same asymptotic distribution as if $b$ were known. This can be verified by checking the sufficient conditions for consistency and asymptotic normality 
in Newey and McFadden (1994, Theorems 2.1 and 3.2). In the empirical work, I use the estimated preference parameters from GMM estimation of the conditional Euler equation (9) to obtain $\widehat{b}$, through equation (17). I then estimate $\theta$ using the moment function $e\left(z_{t}, \theta ; \widehat{b}\right)$. This estimation strategy is consistent with the purpose of estimating the conditional factor model (30), which is to better understand the dynamics of expected returns implied by asset pricing equation (9).

\section{Consumption Data}

\subsection{Source and Construction}

Quarterly consumption data is from the US national accounts. Following convention, nondurable consumption is measured as the sum of real personal consumption expenditures (PCE) on nondurable goods and services. ${ }^{4}$ Nondurable consumption includes food, clothing and shoes, housing, utilities, transportation, and medical care. Items such as clothing and shoes are durable at quarterly frequency, but I include them as part of nondurable consumption to be consistent with previous studies of the CCAPM. Similarly, housing is the service flow imputed from the rental value of houses.

Durable consumption consists of items such as motor vehicles, furniture and appliances, and jewelry and watches. The Bureau of Economic Analysis (BEA) publishes year-end estimates of the chained quantity index for the net stock of consumer durable goods. Using quarterly data for real PCE on durable goods, I construct quarterly series for the stock of durables by equation (1). Implicit in the data for the stock of durables are the depreciation rates used by the BEA for various components of durable goods. The implied depreciation rate for durable goods as a whole is about $6 \%$ per quarter.

Both nondurable consumption and the stock of durables are divided by the population. In matching consumption to returns data, I use "beginning of the period" timing convention, following Campbell (2003). In other words, the consumption data for each quarter is assumed to be the flow on the first, rather than the last, day of the quarter. Although quarterly

\footnotetext{
${ }^{4}$ See Whelan (2000) for issues concerning aggregation of chained national accounts data.
} 
consumption data is available since 1947, the period immediately after the war experienced unusually high durable consumption growth due to the rapid restocking of durable goods. I therefore use data since 1951, following Ogaki and Reinhart (1998). The resulting sample period is 1951:1-2001:4.

\subsection{Basic Description}

Figure 2 is a time series plot of the ratio of the stock of durables to nondurable consumption, that is $D / C$. The series has an upward trend in the postwar sample, which is consistent with the downward trend in the price of durables relative to nondurables. The shaded regions are recessions, from peak to trough, as defined by the National Bureau of Economic Research (NBER). The ratio $D / C$ rises during booms and falls during recessions, implying strong counter-cyclical movements in marginal utility (13), provided that the elasticity of substitution between the goods is high.

Table 1 reports descriptive statistics for nondurable and durable consumption growth, together with those for the three Fama-French factors. (Recall that the growth rate in the stock is the growth rate in the consumption of durable goods.) Nondurable consumption growth has mean $0.51 \%$ and standard deviation $0.54 \%$ per quarter. Durable consumption has mean $0.92 \%$ and standard deviation $0.54 \%$. The correlation between them is 0.19 . The Fama-French factors have low correlation with the two consumption-based factors, especially with durable consumption growth. Durable consumption growth is much more persistent than nondurable consumption growth. The first-order autocorrelations are 0.88 and 0.28 , respectively.

\subsection{Business-Cycle Properties}

Figure 3(a) is a time series plot of the growth rates of nondurable and durable consumption in the postwar sample. Durable consumption growth is strongly pro-cyclical, peaking during booms and bottoming out during recessions. It is therefore a good indicator variable for the business cycle. Nondurable consumption growth is also pro-cyclical, but less so than durable consumption. It tends to fall sharply right at the onset of recessions. Figure 3(b) 
is a time series plot of nondurable consumption growth minus durable consumption growth. The growth rate of durable consumption generally exceeds that of nondurable consumption, except during and immediately after recessions. The series is strongly counter-cyclical, highest at business-cycle troughs and lowest at business-cycle peaks.

To examine the cyclical properties of nondurable consumption in further detail, Figure 4(a) shows the time series for nondurable consumption growth together with the growth rates of two of its components: (1) food and (2) housing. (At the end of 2001, food accounted for $16 \%$ and housing $17 \%$ of consumption expenditures on nondurables.) The figure illustrates the fact that the components of nondurable consumption share the time series properties of its aggregate: low volatility (compared to stock returns), low autocorrelation, and weak cyclicality. Although houses can be thought of as a "durable good", its service flows are more similar to that of "nondurable goods".

Implicit in studies of the CCAPM is the assumption that the various components of nondurable consumption are perfect substitutes. This appears to be a reasonable assumption for the purposes of empirical work since the various components share similar time series properties. Moreover, the gain from explicitly modeling non-separability between the various components of nondurable consumption appears to be small, at least for the purposes of asset pricing. For instance, Piazessi, Schneider, and Tuzel (2003) find that a model that accounts for non-separability between housing and other nondurable goods cannot reconcile the size and value premia. ${ }^{5}$

Figure 4(b) is a time series plot of durable consumption growth together with the growth rates of two of its components: (1) motor vehicles and (2) furniture and appliances. (At the end of 2001, motor vehicles accounted for 30\% and furniture and appliances $45 \%$ of the stock of consumer durables.) The figure illustrates the fact that the components of durable consumption share the time series properties of its aggregate: low volatility (compared to stock returns), high autocorrelation, and strong cyclicality. The consumption of motor vehicles is

\footnotetext{
${ }^{5}$ The test that the pricing errors are jointly zero for the 25 Fama-French portfolios rejects the model. However, Lustig and Van Nieuwerburgh (2002) argue that housing has an important role as collateral in risk-sharing markets. Using the housing-human wealth ratio as a conditioning variable, they find that the conditional CCAPM can explain the size and value premia. Their finding confirms that of Lettau and Ludvigson (2001), who use the consumption-wealth ratio as a conditioning variable.
} 
especially pro-cyclical with sharp falls during recessions. The strong cyclicality of durable consumption is consistent with that of luxury goods (Aït-Sahalia, Parker, and Yogo 2003).

\section{Cross-Sectional Tests}

In this section, I test the cross-sectional implications of the durable consumption model. The test assets are the 25 Fama-French portfolios (Section 5.1), portfolios sorted by bookto-market equity within industry (Section 5.2), and portfolios sorted by market and HML betas (Section 5.3). The empirical results focus on the linear two-factor model (23), rather than the nonlinear model (19) with SDF (14). The main advantage of the linear model is that it makes transparent the central economic finding, that small stocks and value stocks are pro-cyclical. It also makes the results readily comparable to the large literature on crosssectional asset pricing, which has focused on linear factor models. In Section 5.4, I estimate the nonlinear model to support the empirical findings for the linear model.

\subsection{Fama-French Portfolios}

\subsubsection{Data}

Fama and French (1993) construct 25 portfolios by independently sorting stocks into quintiles based on size (i.e. market equity) and book-to-market equity. Data on the Fama-French factors and portfolio returns were obtained from Professor Kenneth French's webpage. Excess

returns are computed by subtracting the 90-day T-bill return, which is from the Center for Research in Security Prices (CRSP) Indices database. Because of the failures of the CAPM and the CCAPM in explaining their returns, the Fama-French portfolios have been the focus of recent work on cross-sectional asset pricing (e.g. Lettau and Ludvigson (2001), Campbell and Vuolteenaho (2002), and Parker and Julliard (2003)).

\subsubsection{Test of Linear Factor Models}

Table 2 reports estimates of the factor risk prices for the CAPM, the Fama-French threefactor model, the CCAPM, and the durable consumption model. Estimation is by two- 
step (efficient) GMM. Standard errors are heteroskedasticity and autocorrelation consistent (HAC), computed by the VARHAC procedure with automatic lag length selection by AIC (see den Haan and Levin (1997)). ${ }^{6}$ The maximum lag length is set to three quarters to account for autocorrelation. The correction for autocorrelation is especially important in estimating the durable consumption model due to the persistence of durable consumption growth.

The CAPM has a positive and significant risk price on the market return. The mean absolute pricing error from the first stage is $0.65 \%$ per quarter. Instead of reporting the mean squared pricing error, I report one minus its ratio to the variance of average portfolio returns, which is called the $R^{2}$, following Campbell and Vuolteenaho (2002). The $R^{2}$ for the CAPM is $-89 \%$, which suggests that the model fits the average T-bill return very poorly. The $J$-test, or the test of overidentifying restrictions, strongly rejects the model.

The Fama-French three-factor model is much more successful than the CAPM. The mean absolute pricing error is $0.26 \%$, and the $R^{2}$ is $66 \%$. The risk price for SMB is not significantly different from zero, while the risk price for HML is significantly positive. Hence, the improvement over the CAPM is mostly captured by the explanatory power of HML. Although the first-stage measures of fit are much better than the CAPM, the $J$-test rejects the model.

For the CCAPM, the risk price for nondurable consumption is positive and significantly different from zero. The large point estimate of 106, which is a consequence of the low volatility of nondurable consumption, is consistent with the literature on the equity premium puzzle. The mean absolute pricing error is $0.33 \%$, and the $R^{2}$ is $38 \%$. Although the CCAPM has better first-stage measures of fit than the CAPM, it falls short of the three-factor model. Moreover, the $J$-test strongly rejects the model.

In the last two columns of Table 2, I report two estimates of the durable consumption model. The first estimate is based only on the moment restrictions used to price the portfolios. The second estimate imposes an additional moment restriction corresponding to the intratemporal FOC (25). In other words, the second estimate forces the model to simultaneously explain the returns on the 25 Fama-French portfolios and the optimal consumption

\footnotetext{
${ }^{6}$ den Haan and Levin (2000) find that the VARHAC covariance matrix estimator performs better than the kernel-based estimators (e.g. Newey and West (1987) and Andrews (1991)) in various Monte Carlo setups.
} 
behavior implied by the FOC. In estimating equation (25), I set $a=0.94$ since the depreciation rate is about $6 \%$ per quarter; the results are not sensitive to reasonable variations in $a$.

Without the intratemporal FOC, the risk price for nondurable consumption is comparable to that estimated for the CCAPM, with a point estimate of 122 . The risk price for durable consumption is larger at 197 and statistically significant. Therefore, the CCAPM, which is a restriction that the risk price on durable consumption be equal to zero, is strongly rejected. Recall that the sum of the risk prices for nondurable and durable consumption is the risk aversion $\gamma$. The point estimate of $\gamma$ is 319, which is a consequence of the low volatility of both nondurable and durable consumption. The model therefore does not resolve the equity premium puzzle. Assuming Cobb-Douglas intraperiod utility (i.e. $\rho=0$ ), the point estimate of $\alpha=b_{2} /\left(b_{1}+b_{2}-1\right)$ is 0.62 . The mean absolute pricing error is $0.20 \%$, and the $R^{2}$ is $77 \%$. Although the $J$-test rejects at the $5 \%$ level, the rejection is solely due to the model's inability to price the small growth portfolio, as discussed below. The results are essentially the same when the intratemporal FOC is imposed.

Figure 5(d) provides a visual summary of the empirical success of the durable consumption model. On the vertical axis is the realized average excess return. On the horizontal axis is the return predicted by the model, based on the first-stage estimates. The points represent the 25 Fama-French portfolios, and the corresponding vertical distance to the diagonal line represents the pricing error. The pricing errors for the durable consumption model are much smaller than those for (a) the CAPM and (c) the CCAPM. It even outperforms (b) the Fama-French three-factor model.

\subsubsection{Estimation Without the Small Growth Portfolio}

Figure 5 reveals the small growth portfolio (i.e. the lowest quintile in both size and bookto-market equity) is an outlier for all the linear factor models. For the durable consumption model, its pricing error is nearly 1\%. D'Avolio (2002) and Lamont and Thaler (2003) document limits to arbitrage, due to short-sale constraints, for the types of stocks that are generally characterized as small growth. It is perhaps unsurprising then that these frictionless equilibrium models have difficulty explaining the small growth portfolio. 
In Table 3, I report estimates of the linear factor models using 24 of the Fama-French portfolios, excluding the small growth portfolio. The $R^{2}$ of the durable consumption model improves from $77 \%$ to $81 \%$. In comparison, the $R^{2}$ of the Fama-French three-factor model improves from $66 \%$ to $74 \%$. The $J$-test fails to reject the durable consumption model at the $5 \%$ level, both with and without the intratemporal FOC. The null hypothesis that the pricing errors are jointly zero is rejected for the other three models.

\subsubsection{Consumption Betas}

To better understand the success of the durable consumption model, Table 4 reports the nondurable and durable consumption betas implied by the first-stage GMM estimates. Panel A reports the average excess returns for the 25 Fama-French portfolios sorted by size and book-to-market equity. Reading down the columns of the panel, average returns decrease in size for a given book-to-market equity quintile. The only exception is for low book-tomarket stocks, whose average returns roughly increase in size. Reading across the rows of the panel, average returns increase in book-to-market equity for a given size quintile. The table confirms the well-known size and value premia.

Panel $\mathrm{B}$ of the table reports the nondurable consumption betas. Reading down the columns of the panel, nondurable consumption beta decreases in size for a given book-tomarket equity quintile. This pattern is broadly consistent with the size premium. Reading across the rows of the panel, nondurable consumption beta also increases in book-to-market equity for a given size quintile. However, the variation in beta across book-to-market equity is relatively small compared to the variation across size. The difference in nondurable consumption beta between small and big stocks is at least 1.36 (for the lowest book-to-market quintile). On the other hand, the difference in beta between high and low book-to-market stocks is at most 0.95 (for size quintile 3 ). The relatively small variation in nondurable consumption beta across book-to-market equity explains why the CCAPM fails to explain the value premium.

Panel $\mathrm{C}$ of the table reports the durable consumption betas. Reading down the columns of the panel, durable consumption beta decreases in size for a given book-to-market equity quintile, with exception of low book-to-market stocks. This is consistent with the pattern in 
average returns across the size quintiles. Moreover, durable consumption beta increases in book-to-market equity for a given size quintile, explaining the value premium. The difference in durable consumption beta between high and low book-to-market stocks is in general larger than that difference between small and big stocks. For instance, the difference in beta between high and low book-to-market stocks is 1.54 for the median size quintile. On the other hand, the difference in beta between small and big stocks is only 0.20 for the median book-to-market equity quintile. Roughly speaking, durable consumption beta accounts for the variation in average returns across book-to-market equity (i.e. value premium), while nondurable consumption beta accounts for the variation in average returns across size (i.e. size premium).

\subsection{Portfolios Sorted by Book-to-Market Equity within Industry}

To examine the value premium in more detail, I now test the durable consumption model on portfolios sorted by book-to-market equity within industry. The question is whether value stocks, that is stocks with high book-to-market equity relative to other stocks in the same industry, have high consumption betas that account for their premia.

\subsubsection{Portfolio Formation}

The portfolios are formed using returns on ordinary common equity, traded in NYSE, AMEX, or Nasdaq, in the CRSP Monthly Stock database. In June of each year $t$, stocks are sorted into eight industries based on their two-digit SIC codes: (1) nondurables manufacturing, (2) durables manufacturing, (3) other manufacturing, (4) nondurables retail, (5) durables retail, (6) services, (7) finance, and (8) natural resource. Within each industry, stocks are then sorted into three levels of book-to-market equity using breakpoints of 30th and 70th percentiles, based on its value in December of $t-1$. Once the 24 portfolios are formed, their value-weighted returns are tracked from July of $t$ through June of $t+1$.

The industry definitions are designed to create variation in book-to-market equity that is independent of nondurable and durable consumption; see Yogo (2003, Table A3) for the corresponding SIC codes. The book equity data is a merge of historical data from Moody's 
Manuals (available from Professor French's webpage) and COMPUSTAT. I refer to Davis, Fama, and French (2000) for details on the computation of book equity.

\subsubsection{Test of Linear Factor Models}

Table 5 reports estimates of linear factor models using the portfolios sorted by book-tomarket equity within industry. For the durable consumption model without the intratemporal FOC, the point estimate of the risk price for durable consumption is 107, which is somewhat smaller than that estimated using the Fama-French portfolios. Since the risk price is significantly different from zero, the CCAPM is rejected. The $R^{2}$ for the model is $69 \%$, compared to $58 \%$ for the Fama-French three-factor model. The $J$-test fails to reject the durable consumption model, while the three-factor model is rejected at the $10 \%$ level. When the intratemporal FOC is imposed, however, the $J$-test rejects the model. This is a rejection of the linear approximation to the FOC; the $J$-test fails to reject the nonlinear model, as shown below.

\subsubsection{Consumption Betas}

Panel A of Table 6 reports the average excess returns for the 24 portfolios. Reading across the rows of the panel, average returns increase in book-to-market equity for each industry. In all industries, the high book-to-market portfolio has higher average returns than the low book-to-market portfolio. Interestingly, the high book-to-market portfolios in the durables manufacturing and durables retail industries have the highest average returns.

Panel $\mathrm{B}$ reports the nondurable consumption betas. Reading across the rows of the panel, nondurable consumption beta increases in book-to-market equity for each industry, except for the nondurables retail and finance industries. Similarly, durable consumption beta (Panel C) increases in book-to-market equity, except for the nondurables manufacturing and durables retail industries. Table 6 makes clear the source of the value premia. In a given industry, high book-to-market stocks have returns that are more pro-cyclical than low bookto-market stocks. Value stocks therefore carry a high premium to compensate the investor for bearing business-cycle risk, measured by consumption growth. 


\subsection{Risk-Sorted Portfolios}

This section examines whether the durable consumption model prices portfolios sorted by risk. Risk-sorted portfolios provide a tough test for asset pricing models by creating a large spread in the post-formation betas. I construct portfolios by sorting stocks based on their preformation market and HML betas. The sort works well in practice. Portfolios with high (low) pre-formation market betas have high (low) post-formation nondurable consumption betas, and portfolios with high (low) pre-formation HML betas have high (low) post-formation durable consumption betas.

The reason for using the market return and HML, rather than nondurable and durable consumption growth, in forming portfolios is that returns are much more noisy than consumption. Therefore, pre-formation consumption betas are too noisy and fails to create the desired spread in the post-formation betas. The results for portfolios sorted by nondurable and durable consumption betas are reported in Yogo (2003, Section B).

\subsubsection{Portfolio Formation}

The portfolios are formed using returns on ordinary common equity, traded in NYSE, AMEX, or Nasdaq, in the CRSP Monthly Stock database. In June of each year $t$, market and HML betas are computed for each stock using monthly returns from January of $t-5$ through December of $t-1$. Stocks with return data missing in any month are dropped from the sample. Then 25 portfolios are formed by independently sorting stocks into quintiles based on the market and HML betas. The value-weighted portfolio returns are then tracked from July of $t$ through June of $t+1$.

\subsubsection{Test of Linear Factor Models}

Table 7 reports estimates of the durable consumption model using the portfolios sorted by market and HML betas. Without the intratemporal FOC, the point estimate of the risk price for nondurable consumption is 148. The estimate of the risk price for durable consumption is 83 , which is significantly different from zero, implying a rejection of the CCAPM. The $R^{2}$ is $47 \%$, and the $J$-test fails to reject the model. The results are similar when the intratemporal 
FOC is imposed, although the $J$-test rejects the model in this case. This is due to the limitations of the linear approximation to the FOC, as discussed below.

\subsection{Estimation of the Nonlinear Model}

The empirical work has so far focused on the linearized durable consumption model, which results from a log-linear approximation to the nonlinear SDF. In this section, I estimate the nonlinear model to check the accuracy of the approximation. The estimation also allows for separate identification of the three preference parameters $(\gamma, \rho$, and $\alpha)$ that determine the risk prices for nondurable and durable consumption.

Table 8 reports two estimates of the durable consumption model. The first estimate is based only on the $N$ moment restrictions (19), with the nonlinear SDF (14), used to price the portfolios. The second estimate imposes the unconditional expectation of the intratemporal FOC (15) as an additional moment restriction. In equation (15), I set $(1-\delta) \beta=0.94$ since the depreciation rate is about $6 \%$ per quarter; the results are not sensitive to reasonable variations in this parameter. Estimation is by two-step (efficient) GMM. HAC standard errors are computed by the VARHAC procedure with automatic lag length selection by AIC. Although the errors are in theory a martingale difference sequence, the maximum lag length is set to one quarter to account for the possibility of time aggregation in consumption data (see Hall (1988)).

Panel A reports the estimates using the 25 Fama-French portfolios. Without the intratemporal FOC, the point estimate of $\gamma$ is 543 , which is somewhat larger than the point estimate of 319 for the linearized model (Table 2). The point estimate of $\rho$ is 1 , implying perfect substitutability between nondurables and durables, but the standard error is large. In particular, the Cobb-Douglas case (i.e. $\rho=0$ ) is approximately two standard errors from the point estimate. A plot (not reported) reveals that the GMM objective function is flat in the direction of $\rho$ in the region, roughly $[0,1]$, where it is minimized. In other words, $\rho$ is not identified well enough to distinguish between values corresponding to high elasticity of substitution, although low values $\rho<0$ are easily rejected. The Wald test strongly rejects the CCAPM (i.e. additive separability), which corresponds to the linear restriction $\rho=1-\gamma$.

When the intratemporal FOC is included as an additional moment restriction, the esti- 
mates of $\gamma$ and $\alpha$ are somewhat smaller, but the results are qualitatively similar. Namely, high risk aversion and high elasticity of substitution between the goods are necessary to explain the size and value premia. These estimates that impose the FOC appear to better identify $\rho$ and $\alpha$, which are parameters that govern intratemporal substitution. The Wald test rejects additive separability. The $J$-test fails to reject the model at conventional significance levels.

Panel B reports estimates using the 24 portfolios sorted by book-to-market equity within industry, and Panel C reports estimates using the 25 portfolios sorted by market and HML betas. The parameter estimates are quite similar across the panels. A representative household model with high risk aversion (i.e. $\gamma \approx 400$ ), unit elasticity of substitution between nondurables and durables (i.e. $\rho=0$ ), and a larger budget share for durables (i.e. $\alpha \approx 0.6$ ) appears to price the cross section of stock returns. The $J$-test fails to reject the model, even when the intratemporal FOC is imposed. This suggests that the rejections of the linear model (Tables 5 and 7 ) are a consequence of linearization error in the intertemporal FOC (25), rather than a failure of the FOC itself.

Panel D reports the results when the model is estimated on all 74 portfolios. When the intratemporal FOC is imposed, the estimate of $\gamma$ is 293, and the estimate of $\alpha$ is 0.61 . The estimate of $\rho$ is 0.26 , implying an elasticity of substitution of 1.35 between nondurables and durables. These estimates have much smaller standard errors than those for the individual sets of portfolios (Panels A-C). The $J$-test fails to reject the model. These results confirm the conclusion from the findings for the linear two-factor model, that the model successfully prices the cross section of stock returns.

\section{Time Series Tests}

I now test the time series implications of the durable consumption model. Section 6.2 tests the model by GMM using portfolio returns and instruments that predict returns. Section 6.3 ties these results to the predictability of stock returns. 


\subsection{Data}

For the empirical work in this section, I focus on five portfolios that capture the common variation in returns across the 25 Fama-French portfolios. The first is the market portfolio, which is a value-weighted portfolio for NYSE and AMEX stocks from the CRSP Indices database. The other four are the small stock, the big stock, the high book-to-market, and the low book-to-market portfolios. These portfolios are based on six portfolios sorted by size (breakpoint at the median) and book-to-market equity (breakpoints at the 30th and 70th percentiles). The difference in returns between the small and big stock portfolios is the SMB return. The difference in returns between the high and low book-to-market portfolios is the HML return. See Fama and French (1993) for details on the construction of these portfolios; the data is available from Professor French's webpage. In computing excess returns, the 90-day T-bill return is used as the riskfree rate.

The time series tests of the durable consumption model require instruments that are informative about the state of the economy. In addition to a constant, I use five instruments in the tests: (1) nondurable consumption growth, (2) durable consumption growth, (3) the dividend-price ratio, (4) the value spread, and (5) the long-short yield spread.

The dividend-price ratio for the CRSP value-weighted portfolio is constructed as the sum of dividends over the past four quarters divided by the current price. The dividend-price ratio is related, by a present-value relationship, to the expectation of future returns and dividend growth and therefore predicts returns (Campbell and Shiller 1988a).

The value spread is the difference in book-to-market equity between the high and low book-to-market portfolios. The value spread is related, by a present-value relationship, to the expectation of future returns and profitability and therefore predicts HML returns (Cohen, Polk, and Vuolteenaho 2003). Following Cohen, Polk, and Vuolteenaho, the book-to-market equity in June of year $t$ is the book equity in December of $t-1$ divided by the market equity in June of $t$. The book-to-market equity in the subsequent months from July of $t$ through May of $t+1$ is the book equity in December of $t-1$ divided by that month's market equity.

Following Fama and French (1989), the long yield used in computing the yield spread is Moody's Seasoned Aaa Corporate Bond Yield. The short rate used is the 1-month T-bill 
rate from the CRSP Fama Risk Free Rates database. The yield spread "tends to be low near business-cycle peaks and high near troughs" (Fama and French 1989, p. 30), much like the difference in nondurable and durable consumption growth (Figure 3(b)).

\subsection{Estimation of the Conditional Euler Equation}

\subsubsection{Excess Stock Returns}

Panel A of Table 9 reports two estimates of the conditional Euler equation (9) for the durable consumption model, using excess stock returns and instruments. The first estimate is based on 30 moment restrictions, corresponding the product of five excess returns with six instruments. The second estimate imposes six additional moment restrictions, corresponding to the product of the intratemporal FOC (15) with the instruments. The instruments are lagged twice to account for time aggregation in consumption data, but the results are similar using once lagged instruments. Estimation is by two-step GMM, as described in Section 5.4.

Including the moment restrictions for the intratemporal FOC, the estimate of $\gamma$ is 338 , implying high risk aversion. The estimate of $\rho$ is -0.08 , with the Cobb-Douglas case (i.e. $\rho=0$ ) within two standard errors. The estimate of $\alpha$ is 0.66 . These estimated preference parameters agree with those for the cross-sectional tests (Table 8). The Wald test strongly rejects the hypothesis of additive separability (i.e. $\rho=1-\gamma$ ), which is consistent with the well-known rejection of the CCAPM. The $J$-test fails to reject the durable consumption model at conventional significance levels.

The fact that the estimates in Tables 8 and 9 agree deserves emphasis since it has important asset pricing implications. On the one hand, the estimates in Table 8 are based on the unconditional Euler equation, using a large cross section of portfolio returns. A successful fit of the model implies that the variation in average returns across stocks can be explained by the SDF (i.e. the marginal rate of substitution in consumption). On the other hand, the estimates in Table 9 are based on the conditional Euler equation, using instruments that are informative about the state of the economy. A successful fit of the model implies that the variation in average stock returns through time can be explained by the SDF. I provide further evidence for the time variation in the equity premium below. 


\subsubsection{Riskfree Rate}

In Panel $\mathrm{B}$ of Table 9, I repeat the estimation in Panel A with six additional moment restrictions, corresponding to the product of the conditional Euler equation (8) for the riskfree rate with the instruments. This allows the identification of the discount factor $\beta$ in addition to the other preference parameters. I again report two sets of estimates, depending on whether the moment restrictions corresponding to the intratemporal FOC are included.

The estimate of $\beta$ is greater than one, implying a negative rate of time preference. This is a consequence of the well-known riskfree rate puzzle. Since the EIS is the inverse of risk aversion under power utility (10), large risk aversion necessarily implies low EIS. However, since consumption grows over time, a negative rate of time preference is necessary to explain the low average riskfree rate. Although preferences with $\beta>1$ may be counter-intuitive, it is not problematic in the sense that competitive equilibria can still exist in an infinite-horizon growth economy (Kocherlakota 1990).

What is more problematic is that the estimates of $\gamma$ and $\alpha$ are much smaller than those reported in Panel A. The inability of the durable consumption model to simultaneously price stock returns and the riskfree rate can be best understood using the log-linear approximation to the riskfree rate (31). Recall that the risk price for durable consumption can be approximated as $b_{2} \approx \alpha \gamma$. Since durable consumption growth is persistent (its first-order autocorrelation is 0.88 ), a large value of $b_{2}$ implies large persistent movements in the riskfree rate. A large risk price for durables, necessary for explaining the cross-sectional and time variation in expected stock returns, results in a "riskfree rate volatility puzzle". I will come back to this issue in Section 7, where I show that the puzzle can be resolved by preferences that separate the EIS from risk aversion.

\subsection{Time Variation in Expected Stock Returns}

\subsubsection{Predictability of Returns}

Stock returns can be predicted by various financial variables such as valuation ratios and asset returns (see the references in the introduction). In a factor pricing model (30), time variation in the equity premium must be explained by time variation in the quantity of risk, 
measured by the conditional covariance of the factors with returns. Therefore, the same variables that predict returns (in equation (34)) must predict the product of the innovation to returns with the factors (in equation (36)). I now document this connection between risk and return for the durable consumption model.

Using the instrumental variables methodology (Section 3.2), I estimate the model with excess log returns on the five portfolios: (1) market, (2) small stock, (3) big stock, (4) high book-to-market, and (5) low book-to-market. The instruments are the same as those used in the GMM estimation of the model: nondurable and durable consumption growth, the dividend-price ratio, the value spread, the yield spread, and a constant. I impose the risk prices implied by the estimated preference parameters, reported in the second column of Table 9. They are 115 and 222 for nondurables and durables, respectively.

Panel A of Table 10 reports estimates of regression model (34), corresponding to the conditional mean of stock returns. Coefficients that are significant at the $5 \%$ level (i.e. $t$ statistic greater than 1.645) are in bold. For all five portfolios, the coefficient on nondurable consumption growth is positive and significant, while the coefficient on durable consumption growth is negative and significant (with exception of the low book-to-market portfolio). This implies that expected stock returns are high when nondurable consumption growth is high and durable consumption growth is low. As shown in Figure 3(b), nondurable consumption growth is high (low) relative to durable consumption growth at business-cycle troughs (peaks). The coefficients therefore imply a counter-cyclical equity premium.

The dividend-price ratio and the yield spread predict returns on the market portfolio, consistent with the findings reported in the literature (e.g. Campbell and Shiller (1988b) and Fama and French (1989)). Since the yield spread is counter-cyclical, its positive coefficient implies that the equity premium is counter-cyclical. The value spread reliably predicts returns on all five portfolios.

Panel B of Table 10 reports estimates of regression model (35), corresponding to the conditional variance of stock returns. The squared innovation to returns is less predictable than returns. Moreover, the coefficients are much smaller in magnitude than those for returns (Panel A), which implies the conditional variance has a relatively small contribution in the movements in expected returns (i.e. left side of equation (32)). 
Panel A of Table 11 reports estimates of regression model (36), where the factor is nondurable consumption growth. The dividend-price ratio and the value spread reliably predict the product of the innovation to returns with nondurable consumption growth. This implies that the conditional covariance of returns with nondurable consumption growth is high when the dividend-price ratio and the value spread are high.

Panel B reports estimates of regression model (36), where the factor is durable consumption growth. Nondurable consumption growth predicts the product of the innovation to returns with durable consumption growth positively, while durable consumption growth predicts it negatively. The yield spread predicts the product positively. This implies that the conditional covariance of returns with durable consumption growth is high when (1) nondurable consumption growth is high relative to durable consumption growth or (2) the yield spread is high. In other words, the conditional covariance of returns with durable consumption growth is counter-cyclical.

To summarize, Tables 10-11 have uncovered some interesting facts about the predictability of stock returns. On the one hand, the dividend-price ratio and the value spread predict returns because they predict nondurable consumption risk, that is the product of the innovation to returns with nondurable consumption growth. On the other hand, nondurable and durable consumption growth and the yield spread predict returns because they predict durable consumption risk, that is the product of the innovation to returns with durable consumption growth. This is consistent with the implications of the conditional factor model (32); time variation in expected returns must be accounted for by time variation in the conditional covariance of returns with either nondurable or durable consumption growth.

\subsubsection{Variance Decomposition of Returns}

Figure 6 is a time series plot of the market premium (i.e. expected excess returns on the market portfolio), implied by the estimates in Tables 10-11. The dark line represents the total market premium, $\mathbf{E}_{t-1}\left[r_{i t}\right]+\operatorname{Var}_{t-1}\left(r_{i t}\right) / 2$, and the light line represents the part due to durables, $b_{2} \operatorname{Cov}_{t-1}\left(\Delta d_{t}, r_{i t}\right)$. The difference, of course, is the premium due to nondurables, $b_{1} \operatorname{Cov}_{t-1}\left(\Delta c_{t}, r_{i t}\right)$. The plot reveals two interesting facts. First, the two lines tend to overlap, which implies that most of the time variation in the equity premium is driven by the time 
variation in durable consumption risk. Second, the equity premium is strongly countercyclical, highest at business-cycle troughs and lowest at business-cycle peaks. Similar plots for the premium on the other four portfolios are reported in Yogo (2003, Figures A1-A2).

The plot of the market premium resembles the plot of the difference between nondurable and durable consumption growth (Figure 3(b)). During a recession, durable consumption falls sharply relative to nondurable consumption, causing the marginal utility of consumption to rise sharply. This causes the market premium to rise sharply at the business-cycle trough. As durable consumption rises relative to nondurable consumption during the subsequent boom, marginal utility falls gradually, and so does the market premium. Time variation in the market premium simply reflects time variation in risk, measured by the marginal utility of consumption.

Table 12 reports the mean, the standard deviation, and the first-order autocorrelation of expected excess returns on the five portfolios. It also reports a variance decomposition of expected returns into the fraction due to nondurables premium, durables premium, and two times the covariance between the two premia. A large fraction of the variation in expected returns is due to variation in the durables premium. For instance, the nondurables premium only accounts for $33 \%$ of the variance in the market premium, while the durables premium accounts for $98 \%$. (-31\% is accounted for by the covariance between the two premia.) This explains why the CCAPM fails to explain the time variation in expected returns; it misses an important component of the cyclical variation in expected returns by ignoring the durables premium.

\section{$7 \quad$ Riskfree Rate Puzzle}

As noted in Section 6.2, the durable consumption model runs into a riskfree rate volatility puzzle. To assess the magnitude of the problem, I compute the implied riskfree rate using equation (31) and plot its time series in Figure 7(a). The risk prices for nondurables and durables are the same as those used to generate the implied market premium in Figure 6. I also use the same instruments to model the conditional moments of consumption growth. The rate of time preference $\bar{r}=0$. 
The expected riskfree rate has a mean $224 \%$ and fluctuates in the range of $-200 \%$ to $500 \%$ per quarter! Most of the variation in the riskfree rate is due to intertemporal substitution (i.e. predictable movements in the first moment of consumption growth) rather than precautionary savings (i.e. predictable movements in the second moments). The large volatility results from a combination of the large risk price for durables and the high persistence of durable consumption growth. The expected riskfree rate is essentially a magnified version of durable consumption growth, shown in Figure 3(a).

\subsection{OCE Preferences}

In order to resolve the riskfree rate puzzle, I introduce preferences that allow for separation of the EIS from risk aversion. This allows me to retain the large risk price for durables, necessary for explaining expected stock returns, while getting rid of the large implied volatility in the riskfree rate. The derivations of the equations in this section are contained in Yogo (2003, Section C).

Household preferences are a generalization of ordinal certainty equivalent (OCE) preferences (Selden 1978) to the two good case. OCE preferences have been used in related empirical work by Hall (1985) and Attanasio and Weber (1989). The household's problem is the same as in Section 1, except his objective function (2) is now

$$
\sum_{t=0}^{\infty} \beta^{t} \frac{\mathbf{E}_{0}\left[v_{t}^{1-\gamma}\right]^{\frac{1-\sigma}{1-\gamma}}}{1-\sigma}
$$

where $v_{t}=v\left(C_{t}, D_{t}\right)$. The parameter $\gamma>0$ governs risk aversion, that is preferences over uncertain future utility flow. The parameter $\sigma>0$ governs intertemporal substitution, that is the willingness to substitute the certainty equivalent of utility flow over time. In the special case $\gamma=\sigma$, the EIS $1 / \sigma$ is the inverse of risk aversion $\gamma$, and the objective function reduces to (2).

The household's FOC results in an Euler equation

$$
\mathbf{E}_{t-1}\left[\left(\frac{v_{t}}{v_{t-1}}\right)^{1-\gamma}\right]^{\frac{\gamma-\sigma}{1-\gamma}} \mathbf{E}_{t-1}\left[M_{t} R_{i t}\right]=1 .
$$

When $\gamma=\sigma$, this reduces to the Euler equation (8) for the durable consumption model. A nice property of OCE preferences is that equation (9) still holds. In other words, the 
equation that prices excess returns does not change, although gross returns are now priced by equation (42). Intuitively, the gross return on an asset is determined by both intertemporal substitution and risk aversion. In comparing the return of one asset relative to another, the part due to intertemporal substitution cancels, leaving only the part due to risk aversion.

Suppose the intraperiod utility is Cobb-Douglas (i.e. $\rho=0$ ). Define the functions $b_{1}(x)=x+\alpha(1-x)$ and $b_{2}(x)=-\alpha(1-x)$. By a second-order log-linear approximation of equation (42) for the riskfree rate,

$$
\begin{aligned}
r_{0 t}= & \bar{r}+b_{1}(\sigma) \mathbf{E}_{t-1}\left[\Delta c_{t}\right]+b_{2}(\sigma) \mathbf{E}_{t-1}\left[\Delta d_{t}\right] \\
& -\frac{b_{1}(\gamma)+b_{1}(\sigma)\left(b_{1}(\gamma)-1\right)}{2} \operatorname{Var}_{t-1}\left(\Delta c_{t}\right)-\frac{b_{2}(\gamma) b_{2}(\sigma)}{2} \operatorname{Var}_{t-1}\left(\Delta d_{t}\right) \\
& -b_{1}(\sigma) b_{2}(\gamma) \operatorname{Cov}_{t-1}\left(\Delta c_{t}, \Delta d_{t}\right) .
\end{aligned}
$$

Note that the part due to intertemporal substitution now depends on $\sigma$, rather than $\gamma$. There are two special cases of interest. When $\gamma=\sigma$, this equation reduces to the riskfree rate under the durable consumption model (i.e. equation (31)). When $\sigma=1, b_{2}(\sigma)=0$ and

$$
r_{0 t}=\bar{r}+\mathbf{E}_{t-1}\left[\Delta c_{t}\right]+\frac{1}{2} \operatorname{Var}_{t-1}\left(\Delta c_{t}\right)-\operatorname{Cov}_{t-1}\left(\Delta c_{t}, b_{1}(\gamma) \Delta c_{t}+b_{2}(\gamma) \Delta d_{t}\right)
$$

Note that the riskfree rate does not depend on $\mathbf{E}_{t-1}\left[\Delta d_{t}\right]$ in this case. An EIS close to one should therefore get rid of the persistent variation in the riskfree rate caused by durable consumption growth.

A problem with OCE preferences is dynamic inconsistency. Because the certainty equivalent of future utility depends on today's expectations, today's consumption plan will not be carried out when expectations are updated tomorrow. In an economy with a single nondurable consumption good, Epstein and Zin (1989) remedied this problem with recursive utility. It is not known whether Epstein-Zin utility can be extended to the case with two consumption goods, one of which is durable. A durable consumption good prevents a clean separation of the intratemporal optimization problem from the intertemporal problem.

Leaving these issues aside, OCE preferences are attractive because excess returns can be priced with the same equation as the durable consumption model. Therefore, all the empirical results in Sections 5-6 for excess stock returns continue to hold under OCE preferences. 


\subsection{Time Variation in the Riskfree Rate}

Figure $7(\mathrm{~b})$ is a time series plot of the riskfree rate using equation (43). The rate of time preference $\bar{r}=0$ as before, and $\sigma=1.14$ (EIS equal to 0.88 ) is chosen to minimize the squared difference between the left and right sides of equation (43).

The expected riskfree rate generated by the model is now reasonable, resolving the riskfree rate volatility puzzle. Its mean is $0.26 \%$ per quarter, which is somewhat lower than $0.47 \%$ for the realized rate (i.e. 90-day T-bill return minus inflation in the price index for nondurable goods). The difference is primarily due to an unexpectedly high real interest rate in the 1980's. It is interesting that the expected riskfree rate, generated using only consumption data, tracks some of the variation in the realized rate.

\section{Conclusion}

The findings of this paper suggest that there is much empirical content in the theoretical paradigm of consumption-based asset pricing. The central insight of the CCAPM is that the marginal utility of consumption is the relevant measure of risk for an investor. This paper has shown the marginal utility of consumption, when suitably modeled, can explain the tradeoff between risk and return reflected in the size premium, the value premium, and the time-varying equity premium.

The central ingredient is a non-separable utility function in nondurable and durable consumption, where the elasticity of substitution between the goods is high relative to the additively separable case. Small stocks and value stocks deliver low returns when marginal utility rises, that is during recessions when durable consumption falls. These stocks must therefore have high expected returns to reward the investor for bearing risk. In addition, stocks deliver unexpectedly low returns when marginal utility rises sharply, that is at business-cycle troughs when durable consumption falls sharply relative to nondurable consumption. The equity premium must therefore be high during recessions to reward the investor for bearing risk.

The mechanism through which the durable consumption model generates a countercyclical equity premium is similar to that of the external habit-formation model (Campbell 
and Cochrane 1999). In the Campbell-Cochrane model, the surplus consumption ratio is strongly pro-cyclical and magnifies the counter-cyclicality of marginal utility relative to the canonical CCAPM. In the durable consumption model, the ratio of durable to nondurable consumption is strongly pro-cyclical and magnifies the counter-cyclicality of marginal utility.

Although the durable consumption model can explain both the cross section of expected stock returns and the time variation in the equity premium, it requires rather high risk aversion to do so because of the low volatility of both nondurable and durable consumption. The riskfree rate volatility puzzle caused by high risk aversion can be resolved through preferences that separate the EIS from risk aversion. However, one may still "reject" the model on the grounds that high risk aversion is a priori unreasonable. The risk aversion implied by the Campbell-Cochrane model is also high, and in that model, the riskfree rate volatility puzzle is avoided by having intertemporal substitution exactly offset precautionary savings. I agree with the view that "high risk aversion is inescapable (or at least has not yet been escaped) in the class of identical-agent models that are consistent with the equity premium facts..." (Campbell and Cochrane 1999, p. 243)

Regardless of whether one believes in the representative household model, this paper has uncovered some intriguing facts about stock returns and the business cycle, which should guide future research.

1. Small stocks and value stocks have higher nondurable and durable consumption betas than big stocks and growth stocks. The returns on small stocks and value stocks are more pro-cyclical than those on big stocks and growth stocks.

2. The expected stock return is high (low) when nondurable consumption growth is high (low) relative to durable consumption growth. The equity premium is strongly countercyclical.

3. The conditional covariance of stock returns with durable consumption growth is high (low) when nondurable consumption growth is high (low) relative to durable consumption growth. Stock returns tend to be unexpectedly low (high) during recessions (booms). 


\section{References}

Ait-Sahalia, Yacine, Jonathan A. Parker, and Motohiro Yogo, 2003, Luxury goods and the equity premium, The Journal of Finance, forthcoming.

Andrews, Donald W. K., 1991, Heteroskedasticity and autocorrelation consistent covariance matrix estimation, Econometrica 59, 817-858.

Attanasio, Orazio P., and Guglielmo Weber, 1989, Intertemporal substitution, risk aversion and the Euler equation for consumption, Economic Journal 99, 59-73.

Breeden, Douglas T., 1979, An intertemporal asset pricing model with stochastic consumption and investment opportunities, Journal of Financial Economics 7, 265-296.

, Michael R. Gibbons, and Robert H. Litzenberger, 1989, Empirical test of the consumption-oriented CAPM, The Journal of Finance 44, 231-262.

Breeden, Douglas T., and Robert H. Litzenberger, 1978, Prices of state-contingent claims implicit in option prices, Journal of Business 51, 621-651.

Caballero, Ricardo J., 1993, Durable goods: An explanation for their slow adjustment, Journal of Political Economy 101, 351-384.

Campbell, John Y., 1987, Stock returns and the term structure, Journal of Financial Economics 18, 373-399.

— , 2003, Consumption-based asset pricing, in George M. Constantinides, Milton Harris, and René M. Stulz, ed.: Handbook of the Economics of Finance, vol. 1B . chap. 13, pp. 801-885 (Elsevier: Amsterdam).

— , and John H. Cochrane, 1999, By force of habit: A consumption-based explanation of aggregate stock market behavior, Journal of Political Economy 107, 205-251.

Campbell, John Y., and Robert J. Shiller, 1988a, The dividend-price ratio and expectations of future dividends and discount factors, The Review of Financial Studies 1, 195-228. 
— 1988b, Stock prices, earnings, and expected dividends, The Journal of Finance 43, $661-676$.

Campbell, John Y., and Tuomo Vuolteenaho, 2002, Bad beta, good beta, Working paper, Harvard University.

Cochrane, John H., 2001, Asset Pricing (Princeton University Press: Princeton, NJ).

Cohen, Randolph B., Christopher Polk, and Tuomo Vuolteenaho, 2003, The value spread, The Journal of Finance 58, 609-641.

Davis, James L., Eugene F. Fama, and Kenneth R. French, 2000, Characteristics, covariances, and average returns: 1929 to 1997, The Journal of Finance 55, 389-406.

D'Avolio, Gene, 2002, The market for borrowing stock, Journal of Financial Economics 66, $271-306$.

den Haan, Wouter J., and Andrew T. Levin, 1997, A practitioner's guide to robust covariance matrix estimation, in G.S. Maddala, and C.R. Rao, ed.: Handbook of Statistics, vol. 15 . pp. 299-342 (Elsevier: Amsterdam).

— , 2000, Robust covariance matrix estimation with data-dependent VAR prewhitening order, NBER Technical Working Paper No. 255.

Dunn, Kenneth B., and Kenneth J. Singleton, 1986, Modeling the term structure of interest rates under non-separable utility and durability of goods, Journal of Financial Economics $17,27-55$.

Eichenbaum, Martin, and Lars Peter Hansen, 1990, Estimating models with intertemporal substitution using aggregate time series data, Journal of Business \& Economic Statistics $8,53-69$.

Epstein, Larry G., and Stanley E. Zin, 1989, Substitution, risk aversion, and the temporal behavior of consumption and asset returns: A theoretical framework, Econometrica 57, 937-969. 
Fama, Eugene F., 1991, Efficient capital markets: II, The Journal of Finance 46, 1575-1617.

— , and Kenneth R. French, 1988, Dividend yields and expected stock returns, Journal of Financial Economics 22, 3-24.

— 1989, Business conditions and expected returns on stocks and bonds, Journal of Financial Economics 25, 23-49.

— , 1992, The cross-section of expected stock returns, The Journal of Finance 47, $427-465$.

- 1993, Common risk factors in the returns on stocks and bonds, Journal of Financial Economics 33, 3-56.

Gibbons, Michael R., Stephen A. Ross, and Jay Shanken, 1989, A test of the efficiency of a given portfolio, Econometrica 57, 1121-1152.

Grossman, Sanford J., and Guy Laroque, 1990, Asset pricing and optimal portfolio choice in the presence of illiquid durable consumption goods, Econometrica 58, 25-51.

Hall, Robert E., 1985, Real interest and consumption, NBER Working Paper No. 1694.

— 1988, Intertemporal substitution in consumption, Journal of Political Economy 96, $339-357$.

Hansen, Lars Peter, 1982, Large sample properties of generalized method of moments estimators, Econometrica 50, 1029-1054.

— , and Kenneth J. Singleton, 1982, Generalized instrumental variables estimation of nonlinear rational expectations models, Econometrica 50, 1269-1286.

Harvey, Campbell R., 1989, Time-varying conditional covariances in tests of asset pricing models, Journal of Financial Economics 24, 289-317.

Kandel, Shmuel, and Robert F. Stambaugh, 1990, Expectations and volatility of consumption and asset returns, The Review of Financial Studies 3, 207-232. 
Keim, Donald B., and Robert F. Stambaugh, 1986, Predicting returns in the stock and bond markets, Journal of Financial Economics 17, 357-390.

Kocherlakota, Narayana R., 1990, On the 'discount' factor in growth economies, Journal of Monetary Economics 25, 43-47.

Lamont, Owen A., and Richard H. Thaler, 2003, Can the market add and subtract? Mispricing in tech stock carve-outs, Journal of Political Economy 111, 227-268.

Lettau, Martin, and Sydney Ludvigson, 2001, Resurrecting the (C)CAPM: A cross-sectional test when risk premia are time-varying, Journal of Political Economy 109, 1238-1287.

Lintner, John, 1965, Security prices, risk, and maximal gains from diversification, The Journal of Finance 20, 587-615.

Lustig, Hanno, and Stijn Van Nieuwerburgh, 2002, Housing collateral, consumption insurance, and risk premia, Working paper, University of Chicago.

Mankiw, N. Gregory, and Matthew D. Shapiro, 1986, Risk and return: Consumption beta versus market beta, The Review of Economics and Statistics 68, 452-459.

Mehra, Rajnish, and Edward C. Prescott, 1985, The equity premium: A puzzle, Journal of Monetary Economics 15, 145-161.

Newey, Whitney K., and Daniel McFadden, 1994, Large sample estimation and hypothesis testing, in Robert F. Engle, and Daniel L. McFadden, ed.: Handbook of Econometrics, vol. 4 . chap. 36, pp. 2111-2245 (Elsevier: Amsterdam).

Newey, Whitney K., and Kenneth D. West, 1987, A simple, positive semi-definite, heteroskedasticity and autocorrelation consistent covariance matrix, Econometrica 55, 703708.

Ogaki, Masao, and Carmen M. Reinhart, 1998, Measuring intertemporal substitution: The role of durable goods, Journal of Political Economy 106, 1078-1098.

Pakǒs, Michal, 2003, Asset pricing with durable goods and non-homothetic preferences, Working paper, University of Chicago. 
Parker, Jonathan A., and Christian Julliard, 2003, Consumption risk and cross-sectional returns, Working paper, Princeton University.

Piazessi, Monika, Martin Schneider, and Selale Tuzel, 2003, Housing, consumption, and asset pricing, Working paper, UCLA.

Rubinstein, Mark, 1976, The valuation of uncertain income streams and the pricing of options, Bell Journal of Economics 7, 407-425.

Selden, Larry, 1978, A new representation of preferences over "certain $\times$ uncertain" consumption pairs: The "ordinal certainty equivalent" hypothesis, Econometrica 46, 1045-1060.

Sharpe, William F., 1964, Capital asset prices: A theory of market equilibrium under conditions of risk, The Journal of Finance 19, 425-442.

Weil, Philippe, 1989, The equity premium puzzle and the risk-free rate puzzle, Journal of Monetary Economics 24, 401-421.

Whelan, Karl, 2000, A guide to the use of chain weighted aggregated NIPA data, Working paper, Federal Reserve Board.

Wooldridge, Jeffrey M., 1994, Estimation and inference for dependent processes, in Robert F. Engle, and Daniel L. McFadden, ed.: Handbook of Econometrics, vol. 4 . chap. 45, pp. 2639-2738 (Elsevier: Amsterdam).

Yogo, Motohiro, 2003, Appendix to "A consumption-based explanation of expected stock returns", Working paper, Harvard University. 
Table 1: Descriptive Statistics

\begin{tabular}{|c|c|c|c|c|c|c|c|}
\hline \multirow[t]{2}{*}{ Variable } & \multirow{2}{*}{$\begin{array}{r}\text { Mean } \\
(\%)\end{array}$} & \multirow{2}{*}{$\begin{array}{r}\text { Std Dev } \\
(\%)\end{array}$} & \multirow[t]{2}{*}{ Autocorr } & \multicolumn{4}{|c|}{ Correlation } \\
\hline & & & & Market & $\mathrm{SMB}$ & HML & Nondurables \\
\hline Market & 1.880 & 8.186 & 0.048 & & & & \\
\hline SMB & 0.508 & 5.580 & -0.034 & 0.423 & & & \\
\hline HML & 1.089 & 5.543 & 0.154 & -0.386 & -0.143 & & \\
\hline Nondurables & 0.513 & 0.542 & 0.282 & 0.281 & 0.130 & 0.004 & \\
\hline Durables & 0.915 & 0.535 & 0.875 & -0.110 & -0.038 & 0.036 & 0.192 \\
\hline
\end{tabular}

Notes: The table reports the mean, the standard deviation, and the first-order autocorrelation of the excess market return, the SMB return, the HML return, and nondurable and durable consumption growth. It also reports the correlation between these variables. 
Table 2: Estimation of Linear Factor Models with the Fama-French Portfolios

\begin{tabular}{|c|c|c|c|c|c|}
\hline \multirow[t]{2}{*}{ Factor Price } & \multirow[t]{2}{*}{ CAPM } & \multirow[t]{2}{*}{ Fama-French } & \multirow[t]{2}{*}{ CCAPM } & \multicolumn{2}{|c|}{ Durable Model } \\
\hline & & & & No FOC & $\mathrm{FOC}$ \\
\hline \multirow[t]{2}{*}{ Market } & 2.659 & 4.319 & & & \\
\hline & $(0.829)$ & $(0.983)$ & & & \\
\hline \multirow[t]{2}{*}{ SMB } & & -0.621 & & & \\
\hline & & $(1.274)$ & & & \\
\hline \multirow[t]{2}{*}{ HML } & & 6.225 & & & \\
\hline & & $(1.323)$ & & & \\
\hline \multirow[t]{2}{*}{ Nondurables } & & & 105.619 & 122.345 & 148.855 \\
\hline & & & $(23.555)$ & $(22.084)$ & $(16.417)$ \\
\hline \multirow[t]{2}{*}{ Durables } & & & & 197.139 & 203.264 \\
\hline & & & & $(39.342)$ & $(40.498)$ \\
\hline \multirow[t]{2}{*}{$\gamma$} & & & & 319.484 & 352.119 \\
\hline & & & & $(46.222)$ & $(48.000)$ \\
\hline \multirow[t]{2}{*}{$\alpha($ if $\rho=0)$} & & & & 0.619 & 0.579 \\
\hline & & & & $(0.062)$ & $(0.048)$ \\
\hline MAE (\%) & 0.654 & 0.257 & 0.329 & 0.198 & 0.192 \\
\hline$R^{2}$ & -0.892 & 0.658 & 0.382 & 0.770 & 0.773 \\
\hline \multirow[t]{2}{*}{$J$-test } & 62.998 & 51.503 & 52.475 & 36.475 & 43.386 \\
\hline & $(0.000)$ & $(0.000)$ & $(0.001)$ & $(0.037)$ & $(0.009)$ \\
\hline
\end{tabular}

Notes: The table reports the estimated factor risk prices for the CAPM, the Fama-French three-factor model, the CCAPM, and the durable consumption model. It reports two estimates of the durable consumption model, with and without the intratemporal FOC as an additional moment restriction. The test assets are the 25 Fama-French portfolios sorted by size and book-to-market equity. Estimation is by two-step GMM. HAC standard errors in parentheses. The mean absolute pricing error (MAE) and $R^{2}$ are based on the first-stage estimate. The $p$-value for the $J$-test (test of overidentifying restrictions) in parentheses. 
Table 3: Estimation of Linear Factor Models without the Small Growth Portfolio

\begin{tabular}{|c|c|c|c|c|c|}
\hline \multirow[t]{2}{*}{ Factor Price } & \multirow[t]{2}{*}{ CAPM } & \multirow[t]{2}{*}{ Fama-French } & \multirow[t]{2}{*}{ CCAPM } & \multicolumn{2}{|c|}{ Durable Model } \\
\hline & & & & No FOC & FOC \\
\hline \multirow[t]{2}{*}{ Market } & 3.023 & 3.767 & & & \\
\hline & $(0.781)$ & $(1.004)$ & & & \\
\hline \multirow[t]{2}{*}{$\mathrm{SMB}$} & & -0.349 & & & \\
\hline & & $(1.292)$ & & & \\
\hline \multirow[t]{2}{*}{ HML } & & 5.935 & & & \\
\hline & & (1.337) & & & \\
\hline \multirow[t]{2}{*}{ Nondurables } & & & 138.188 & 158.887 & 160.937 \\
\hline & & & $(26.764)$ & $(23.256)$ & $(17.003)$ \\
\hline \multirow[t]{2}{*}{ Durables } & & & & 179.757 & 127.783 \\
\hline & & & & $(47.592)$ & $(21.464)$ \\
\hline \multirow[t]{2}{*}{$\gamma$} & & & & 338.644 & 288.720 \\
\hline & & & & $(54.980)$ & $(37.017)$ \\
\hline \multirow[t]{2}{*}{$\alpha($ if $\rho=0)$} & & & & 0.532 & 0.444 \\
\hline & & & & $(0.072)$ & $(0.024)$ \\
\hline MAE $(\%)$ & 0.577 & 0.220 & 0.293 & 0.197 & 0.198 \\
\hline$R^{2}$ & -0.693 & 0.740 & 0.485 & 0.805 & 0.805 \\
\hline \multirow[t]{2}{*}{$J$-test } & 51.952 & 43.025 & 38.217 & 32.291 & 12.600 \\
\hline & $(0.001)$ & $(0.003)$ & $(0.024)$ & $(0.073)$ & $(0.960)$ \\
\hline
\end{tabular}

Notes: The test assets are 24 of the Fama-French portfolios, excluding the small growth portfolio (i.e. smallest size and lowest book-to-market equity). See notes to Table 2. 
Table 4: Average Returns and Consumption Betas for the Fama-French Portfolios

\begin{tabular}{|c|c|c|c|c|c|c|}
\hline \multirow[b]{2}{*}{ Size } & \multicolumn{6}{|c|}{ Book-to-Market Equity } \\
\hline & Low & 2 & 3 & 4 & High & High-Low \\
\hline \multicolumn{7}{|c|}{ A. Average Excess Return (\%) } \\
\hline Small & 1.121 & 2.448 & 2.531 & 3.160 & 3.464 & 2.343 \\
\hline 2 & 1.458 & 2.225 & 2.716 & 2.929 & 3.150 & 1.692 \\
\hline 3 & 1.707 & 2.345 & 2.313 & 2.756 & 2.937 & 1.230 \\
\hline 4 & 1.896 & 1.797 & 2.417 & 2.568 & 2.725 & 0.829 \\
\hline Big & 1.686 & 1.652 & 2.015 & 1.987 & 2.140 & 0.454 \\
\hline Small-Big & -0.565 & 0.796 & 0.516 & 1.173 & 1.324 & \\
\hline \multicolumn{7}{|c|}{ B. Nondurable Consumption Beta } \\
\hline Small & 6.425 & 6.635 & 6.386 & 6.309 & 7.149 & 0.724 \\
\hline 2 & 6.164 & 5.621 & 5.940 & 6.209 & 6.726 & 0.561 \\
\hline 3 & 5.709 & 5.693 & 5.601 & 5.883 & 6.660 & 0.951 \\
\hline 4 & 5.302 & 4.692 & 5.105 & 5.863 & 5.780 & 0.477 \\
\hline Big & 5.063 & 3.942 & 3.572 & 4.719 & 4.533 & -0.530 \\
\hline Small-Big & 1.362 & 2.693 & 2.814 & 1.590 & 2.616 & \\
\hline \multicolumn{7}{|c|}{ C. Durable Consumption Beta } \\
\hline Small & -0.444 & -0.030 & 0.675 & 1.253 & 1.396 & 1.840 \\
\hline 2 & -1.108 & -0.044 & 0.869 & 0.668 & 0.710 & 1.818 \\
\hline 3 & -0.612 & 0.035 & 0.502 & 0.868 & 0.925 & 1.537 \\
\hline 4 & -0.083 & -0.407 & 0.249 & 0.931 & 0.861 & 0.943 \\
\hline Big & 0.204 & -0.141 & 0.471 & 0.730 & 0.461 & 0.257 \\
\hline Small-Big & -0.649 & 0.111 & 0.204 & 0.523 & 0.935 & \\
\hline
\end{tabular}

Notes: Panel A reports average excess returns (per quarter) on the 25 Fama-French portfolios sorted by size and book-to-market equity. Panels B and C report nondurable and durable consumption betas, implied by the first-stage GMM estimate of the durable consumption model. The last row reports the difference between small and big stocks, and the last column reports the difference between high and low book-to-market stocks. 
Table 5: Estimation of Linear Factor Models with Portfolios Sorted by Book-to-Market Equity within Industry

\begin{tabular}{lrrrrr}
\hline \hline \multirow{2}{*}{ Factor Price } & CAPM & Fama-French & CCAPM & \multicolumn{2}{c}{ Durable Model } \\
\cline { 4 - 5 } & & & & No FOC & FOC \\
\hline Market & 3.122 & 4.021 & & & \\
& $(0.728)$ & $(1.026)$ & & & \\
SMB & & 0.494 & & & \\
& & $(1.280)$ & & & \\
HML & 5.146 & & & \\
& & $(1.309)$ & & & \\
Nondurables & & & 111.389 & 113.942 & 82.188 \\
& & & $(13.151)$ & $(12.918)$ & $(5.802)$ \\
Durables & & & & 106.582 & 129.969 \\
& & & & $(18.062)$ & $(12.237)$ \\
\hline$\gamma$ & & & & 220.523 & 212.157 \\
& & & & $(21.601)$ & $(16.630)$ \\
$\alpha$ (if $\rho=0)$ & & & & 0.486 & 0.616 \\
& & & & $(0.052)$ & $(0.017)$ \\
\hline MAE (\%) & 0.624 & 0.354 & 0.424 & 0.314 & 0.341 \\
$R^{2}$ & -0.007 & 0.579 & 0.519 & 0.688 & 0.658 \\
$J$-test & 41.834 & 32.293 & 27.102 & 28.125 & 35.251 \\
& $(0.009)$ & $(0.055)$ & $(0.252)$ & $(0.172)$ & $(0.049)$ \\
\hline
\end{tabular}

Notes: The test assets are 24 portfolios sorted by book-to-market equity within industry. Portfolios are formed by first sorting stocks into 8 industries, then sorting into 3 levels of book-to-market equity (breakpoints of 30th and 70th percentiles) within each industry. See notes to Table 2 . 
Table 6: Average Returns and Consumption Betas for Portfolios Sorted by Book-to-Market Equity within Industry

\begin{tabular}{lcccccccccc}
\hline \hline & \multicolumn{1}{c}{ A. Average Return (\%) } & \multicolumn{3}{c}{ B. Nondurable Beta } & \multicolumn{3}{c}{ C. Durable Beta } \\
\cline { 2 - 10 } & \multicolumn{9}{c}{ Book-to-Market Equity } \\
\cline { 2 - 10 } Industry & Low & Med & High & Low & Med & High & Low & Med & High \\
\hline Manufacturing: & & & & & & & & & \\
$\quad$ Nondurables & 1.904 & 2.271 & 2.817 & 4.088 & 4.401 & 5.225 & 0.533 & 0.394 & 0.457 \\
$\quad$ Durables & 1.727 & 2.396 & 3.746 & 5.358 & 5.595 & 8.151 & -1.184 & -0.418 & 1.691 \\
$\quad$ Other & 1.516 & 1.894 & 2.664 & 4.822 & 3.749 & 4.982 & -0.132 & 0.488 & 1.565 \\
Retail: & & & & & & & & & \\
$\quad$ Nondurables & 1.961 & 2.627 & 2.522 & 5.470 & 4.686 & 4.959 & -0.679 & -0.381 & -0.107 \\
$\quad$ Durables & 2.260 & 2.049 & 3.480 & 5.412 & 5.712 & 5.943 & -0.902 & -1.402 & -0.922 \\
Services & 1.670 & 1.298 & 2.182 & 4.104 & 3.191 & 5.429 & -1.376 & -0.674 & 0.806 \\
Finance & 1.527 & 2.586 & 3.117 & 4.508 & 5.035 & 4.492 & -0.567 & 0.302 & 0.400 \\
Natural Resource & 0.277 & 1.627 & 2.928 & 1.632 & 3.470 & 4.732 & -0.666 & 0.789 & 2.185 \\
\hline
\end{tabular}

Notes: Panel A reports average excess returns (per quarter) on 24 portfolios sorted by book-to-market equity within industry. Panels $\mathrm{B}$ and $\mathrm{C}$ report nondurable and durable consumption betas, implied by the first-stage GMM estimate of the durable consumption model. See notes to Table 5 for details on portfolio formation. 
Table 7: Estimation of Linear Factor Models with Portfolios Sorted by Market and HML Betas

\begin{tabular}{|c|c|c|c|c|c|}
\hline \multirow[t]{2}{*}{ Factor Price } & \multirow[t]{2}{*}{ CAPM } & \multirow[t]{2}{*}{ Fama-French } & \multirow[t]{2}{*}{ CCAPM } & \multicolumn{2}{|c|}{ Durable Model } \\
\hline & & & & No FOC & FOC \\
\hline \multirow[t]{2}{*}{ Market } & 2.545 & 5.121 & & & \\
\hline & $(0.647)$ & $(1.012)$ & & & \\
\hline \multirow[t]{2}{*}{ SMB } & & -4.569 & & & \\
\hline & & (1.859) & & & \\
\hline \multirow[t]{2}{*}{ HML } & & 4.989 & & & \\
\hline & & $(1.459)$ & & & \\
\hline \multirow[t]{2}{*}{ Nondurables } & & & 143.673 & 147.880 & 136.495 \\
\hline & & & $(21.288)$ & $(22.017)$ & (15.394) \\
\hline \multirow[t]{2}{*}{ Durables } & & & & 83.499 & 103.762 \\
\hline & & & & $(27.213)$ & $(19.065)$ \\
\hline \multirow[t]{2}{*}{$\gamma$} & & & & 231.379 & 240.257 \\
\hline & & & & $(32.741)$ & $(32.560)$ \\
\hline \multirow[t]{2}{*}{$\alpha($ if $\rho=0)$} & & & & 0.362 & 0.434 \\
\hline & & & & $(0.087)$ & $(0.029)$ \\
\hline MAE $(\%)$ & 0.518 & 0.257 & 0.328 & 0.232 & 0.262 \\
\hline$R^{2}$ & -1.783 & 0.305 & -0.053 & 0.473 & 0.311 \\
\hline \multirow[t]{2}{*}{$J$-test } & 24.641 & 18.355 & 28.806 & 29.761 & 39.878 \\
\hline & $(0.425)$ & $(0.685)$ & $(0.228)$ & $(0.156)$ & $(0.022)$ \\
\hline
\end{tabular}

Notes: The test assets are 25 portfolios formed by independently sorting stocks into quintiles based on pre-formation market and HML betas. See notes to Table 2. 


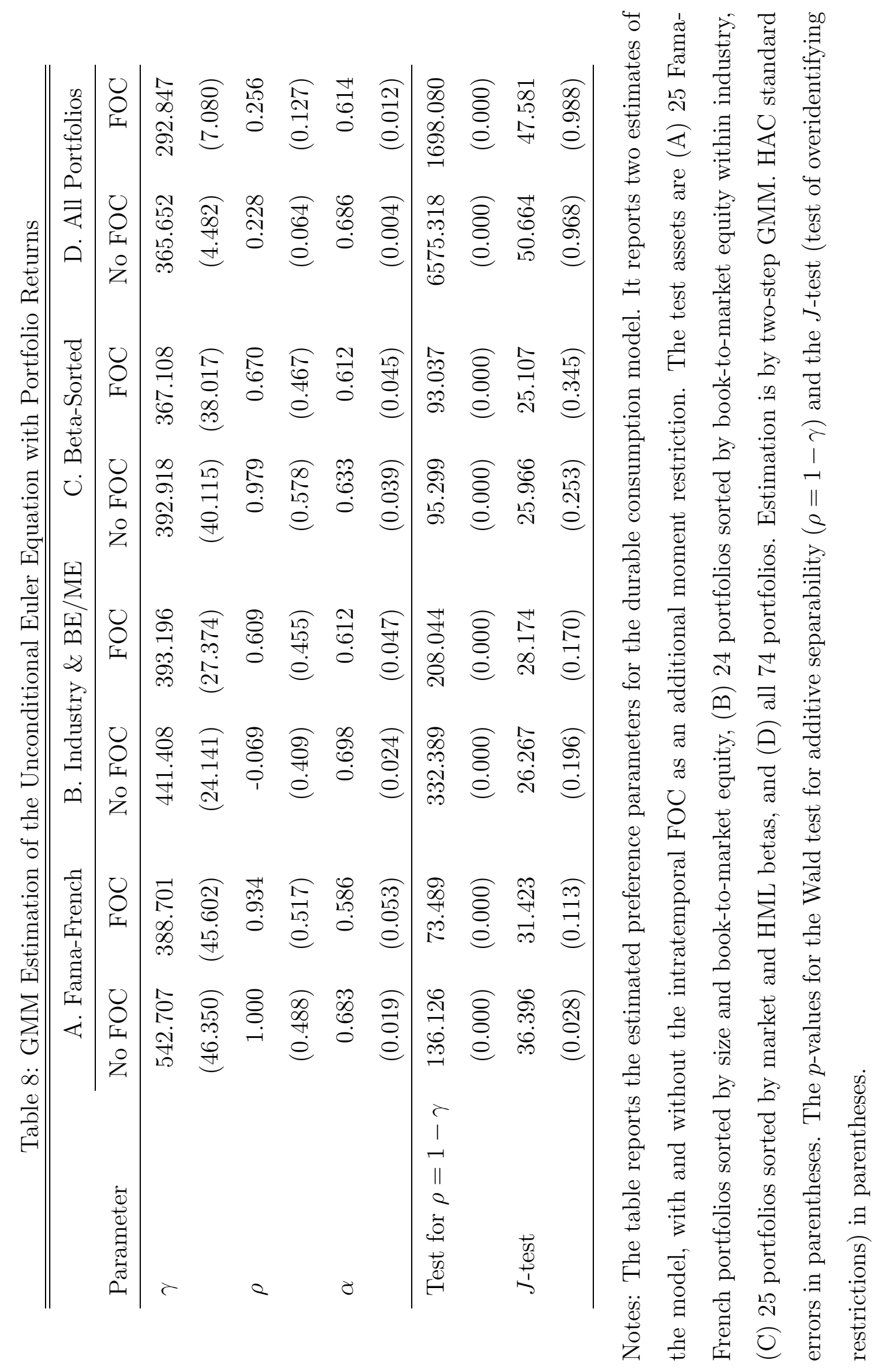


Table 9: GMM Estimation of the Conditional Euler Equation with Stock Returns and Instruments

\begin{tabular}{lrrrr}
\hline \hline \multirow{2}{*}{ Parameter } & \multicolumn{2}{c}{ A. Without T-bill } & \multicolumn{2}{c}{ B. With T-bill } \\
\cline { 2 - 5 } & No FOC & FOC & No FOC & FOC \\
\hline$\gamma$ & 478.467 & 337.678 & 158.861 & 114.309 \\
& $(32.289)$ & $(20.012)$ & $(12.221)$ & $(12.887)$ \\
$\rho$ & 1.000 & -0.080 & -3.053 & -0.829 \\
& $(0.316)$ & $(0.063)$ & $(1.664)$ & $(0.111)$ \\
$\alpha$ & 0.651 & 0.661 & 0.491 & 0.165 \\
$\beta$ & $(0.017)$ & $(0.007)$ & $(0.129)$ & $(0.006)$ \\
& & & 2.193 & 1.660 \\
& & & $(0.107)$ & $(0.095)$ \\
\hline \multirow{2}{*}{ Test for $\rho=1-\gamma$} & 216.778 & 283.505 & 166.341 & 76.010 \\
& $(0.000)$ & $(0.000)$ & $(0.000)$ & $(0.000)$ \\
$J$-test & 36.235 & 42.123 & 62.738 & 90.191 \\
& $(0.110)$ & $(0.133)$ & $(0.001)$ & $(0.000)$ \\
\hline
\end{tabular}

Notes: The test assets are the CRSP value-weighted portfolio, the small stock portfolio, the big stock portfolio, the high book-to-market portfolio, the low book-to-market portfolio, and the 90-day T-bill (only in Panel B). The instruments are second lags of nondurable and durable consumption growth, the log dividend-price ratio, the value spread, the yield spread, and a constant. See notes to Table 8. 
Table 10: Conditional Mean and Variance of Stock Returns

\begin{tabular}{|c|c|c|c|c|c|}
\hline \multirow[t]{2}{*}{ Instrument } & \multirow[t]{2}{*}{ Market } & \multicolumn{2}{|c|}{ Size } & \multicolumn{2}{|c|}{$\mathrm{BE} / \mathrm{ME}$} \\
\hline & & Small & Big & High & Low \\
\hline \multicolumn{6}{|c|}{ A. Conditional Mean } \\
\hline \multirow[t]{2}{*}{ Nondurables } & 1.347 & 2.131 & 1.493 & 2.269 & 1.612 \\
\hline & $(0.601)$ & $(1.059)$ & $(0.625)$ & $(0.876)$ & $(0.883)$ \\
\hline \multirow[t]{2}{*}{ Durables } & -1.459 & -1.661 & -1.652 & -1.841 & -1.395 \\
\hline & $(0.666)$ & $(0.997)$ & $(0.656)$ & $(0.751)$ & $(0.966)$ \\
\hline \multirow[t]{2}{*}{ Dividend-Price } & 0.024 & 0.027 & 0.021 & 0.029 & 0.020 \\
\hline & $(0.013)$ & $(0.019)$ & $(0.013)$ & $(0.014)$ & $(0.018)$ \\
\hline \multirow[t]{2}{*}{ Value Spread } & 0.036 & 0.050 & 0.034 & 0.040 & 0.051 \\
\hline & $(0.015)$ & $(0.026)$ & $(0.016)$ & $(0.020)$ & $(0.024)$ \\
\hline \multirow[t]{2}{*}{ Yield Spread } & 0.531 & 0.643 & 0.567 & 0.567 & 0.571 \\
\hline & $(0.285)$ & $(0.449)$ & $(0.290)$ & $(0.361)$ & $(0.406)$ \\
\hline \multicolumn{6}{|c|}{ B. Conditional Variance } \\
\hline \multirow[t]{2}{*}{ Nondurables } & 0.193 & -0.702 & 0.035 & -0.471 & -0.081 \\
\hline & $(0.076)$ & $(0.187)$ & $(0.069)$ & $(0.131)$ & $(0.148)$ \\
\hline \multirow[t]{2}{*}{ Durables } & -0.217 & 0.181 & -0.210 & -0.024 & -0.060 \\
\hline & $(0.089)$ & $(0.169)$ & $(0.080)$ & $(0.106)$ & $(0.156)$ \\
\hline \multirow[t]{2}{*}{ Dividend-Price } & 0.002 & -0.002 & 0.002 & 0.002 & 0.000 \\
\hline & $(0.002)$ & $(0.004)$ & $(0.002)$ & $(0.003)$ & $(0.003)$ \\
\hline \multirow[t]{2}{*}{ Value Spread } & 0.005 & 0.011 & 0.006 & 0.008 & 0.013 \\
\hline & $(0.002)$ & $(0.006)$ & $(0.002)$ & $(0.004)$ & $(0.005)$ \\
\hline \multirow[t]{2}{*}{ Yield Spread } & -0.056 & -0.027 & -0.038 & -0.052 & -0.013 \\
\hline & $(0.049)$ & $(0.084)$ & $(0.045)$ & $(0.056)$ & $(0.080)$ \\
\hline
\end{tabular}

Notes: The table reports the conditional mean and variance of excess returns on the CRSP value-weighted portfolio, the small stock portfolio, the big stock portfolio, the high book-tomarket portfolio, and the low book-to-market portfolio. The conditional mean (variance) is estimated from a regression of returns (squared innovation to returns) onto the instruments. The instruments are lags of nondurable and durable consumption growth, the log dividendprice ratio, the value spread, the yield spread, and a constant. Estimation is by two-step GMM. HAC standard errors in parentheses. Coefficients significant at the $5 \%$ level are in bold. 
Table 11: Conditional Covariance of Stock Returns with Consumption Growth

\begin{tabular}{|c|c|c|c|c|c|}
\hline \multirow[t]{2}{*}{ Instrument } & \multirow[t]{2}{*}{ Market } & \multicolumn{2}{|c|}{ Size } & \multicolumn{2}{|c|}{$\mathrm{BE} / \mathrm{ME}$} \\
\hline & & Small & Big & High & Low \\
\hline \multicolumn{6}{|c|}{ A. Nondurable Consumption } \\
\hline \multirow[t]{2}{*}{ Nondurables } & -0.482 & -0.217 & -0.363 & 0.074 & -0.656 \\
\hline & $(0.310)$ & $(0.567)$ & $(0.317)$ & $(0.481)$ & $(0.483)$ \\
\hline \multirow[t]{2}{*}{ Durables } & -0.333 & -0.423 & -0.510 & -0.740 & -0.266 \\
\hline & $(0.312)$ & $(0.537)$ & $(0.310)$ & $(0.422)$ & $(0.481)$ \\
\hline \multirow[t]{2}{*}{ Dividend-Price } & 0.018 & 0.034 & 0.022 & 0.036 & 0.023 \\
\hline & $(0.007)$ & $(0.013)$ & $(0.008)$ & $(0.011)$ & $(0.011)$ \\
\hline \multirow[t]{2}{*}{ Value Spread } & 0.033 & 0.047 & 0.038 & 0.047 & 0.047 \\
\hline & $(0.012)$ & $(0.022)$ & $(0.012)$ & $(0.018)$ & $(0.019)$ \\
\hline \multirow[t]{2}{*}{ Yield Spread } & -0.110 & -0.089 & -0.137 & -0.159 & -0.082 \\
\hline & $(0.129)$ & $(0.190)$ & $(0.130)$ & $(0.161)$ & $(0.180)$ \\
\hline \multicolumn{6}{|c|}{ B. Durable Consumption } \\
\hline \multirow[t]{2}{*}{ Nondurables } & 0.899 & 0.912 & 0.867 & 0.876 & 1.046 \\
\hline & $(0.244)$ & $(0.511)$ & $(0.253)$ & $(0.405)$ & $(0.406)$ \\
\hline \multirow[t]{2}{*}{ Durables } & -0.532 & -0.487 & -0.526 & -0.449 & -0.503 \\
\hline & $(0.312)$ & $(0.514)$ & $(0.304)$ & $(0.371)$ & $(0.475)$ \\
\hline \multirow[t]{2}{*}{ Dividend-Price } & 0.002 & -0.006 & -0.002 & -0.006 & -0.003 \\
\hline & $(0.006)$ & $(0.010)$ & $(0.006)$ & $(0.008)$ & $(0.009)$ \\
\hline \multirow[t]{2}{*}{ Value Spread } & 0.000 & 0.001 & -0.003 & -0.004 & 0.002 \\
\hline & $(0.008)$ & $(0.014)$ & $(0.008)$ & $(0.010)$ & $(0.013)$ \\
\hline \multirow[t]{2}{*}{ Yield Spread } & 0.283 & 0.329 & 0.317 & 0.326 & 0.296 \\
\hline & $(0.112)$ & $(0.186)$ & $(0.114)$ & $(0.141)$ & $(0.166)$ \\
\hline
\end{tabular}

Notes: The table reports the conditional covariance of excess returns with (A) nondurable and (B) durable consumption growth. The conditional covariance, reported in percent, is estimated from a regression of consumption growth times the innovation to returns onto the instruments. See notes to Table 10. 
Table 12: Variance Decomposition of Expected Stock Returns

\begin{tabular}{lrrrrrr}
\hline \hline \multirow{2}{*}{ Return } & Mean & Std Dev & Autocorr & \multicolumn{3}{c}{ \% of Variance due to } \\
\cline { 5 - 8 } & $(\%)$ & $(\%)$ & & Nondurables & Durables & Covariance \\
\hline Market & 1.712 & 1.584 & 0.659 & 33.154 & 97.539 & -30.693 \\
Small & 2.490 & 1.891 & 0.623 & 47.415 & 85.011 & -32.427 \\
Big & 1.901 & 1.660 & 0.661 & 39.602 & 94.816 & -34.418 \\
Small-Big & 0.589 & 0.429 & 0.695 & 79.108 & 126.971 & -106.079 \\
High BE/ME & 2.502 & 1.908 & 0.610 & 53.546 & 75.730 & -29.276 \\
Low BE/ME & 1.948 & 1.775 & 0.632 & 44.657 & 96.767 & -41.425 \\
High-Low & 0.554 & 0.628 & 0.825 & 128.087 & 24.691 & -52.779 \\
\hline
\end{tabular}

Notes: The table reports the mean, the standard deviation, and the first-order autocorrelation of expected excess returns (per quarter) on the CRSP value-weighted portfolio, the small stock portfolio, the big stock portfolio, the high book-to-market portfolio, and the low book-to-market portfolio. It also reports a decomposition of the variance into the part due to nondurables premium, durables premium, and the covariance between the two premia. 


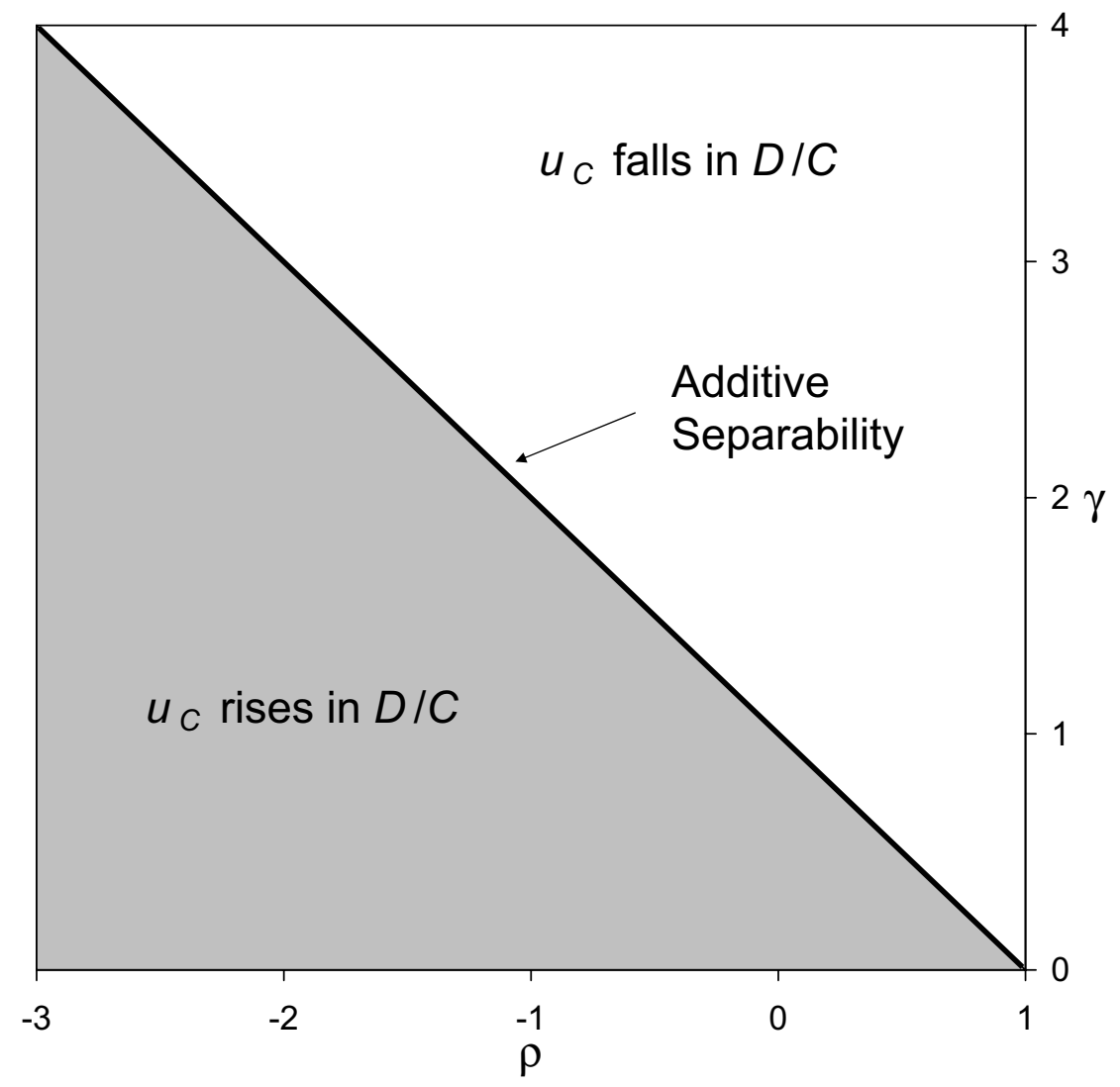

Figure 1: Marginal Utility of Nondurable Consumption. 


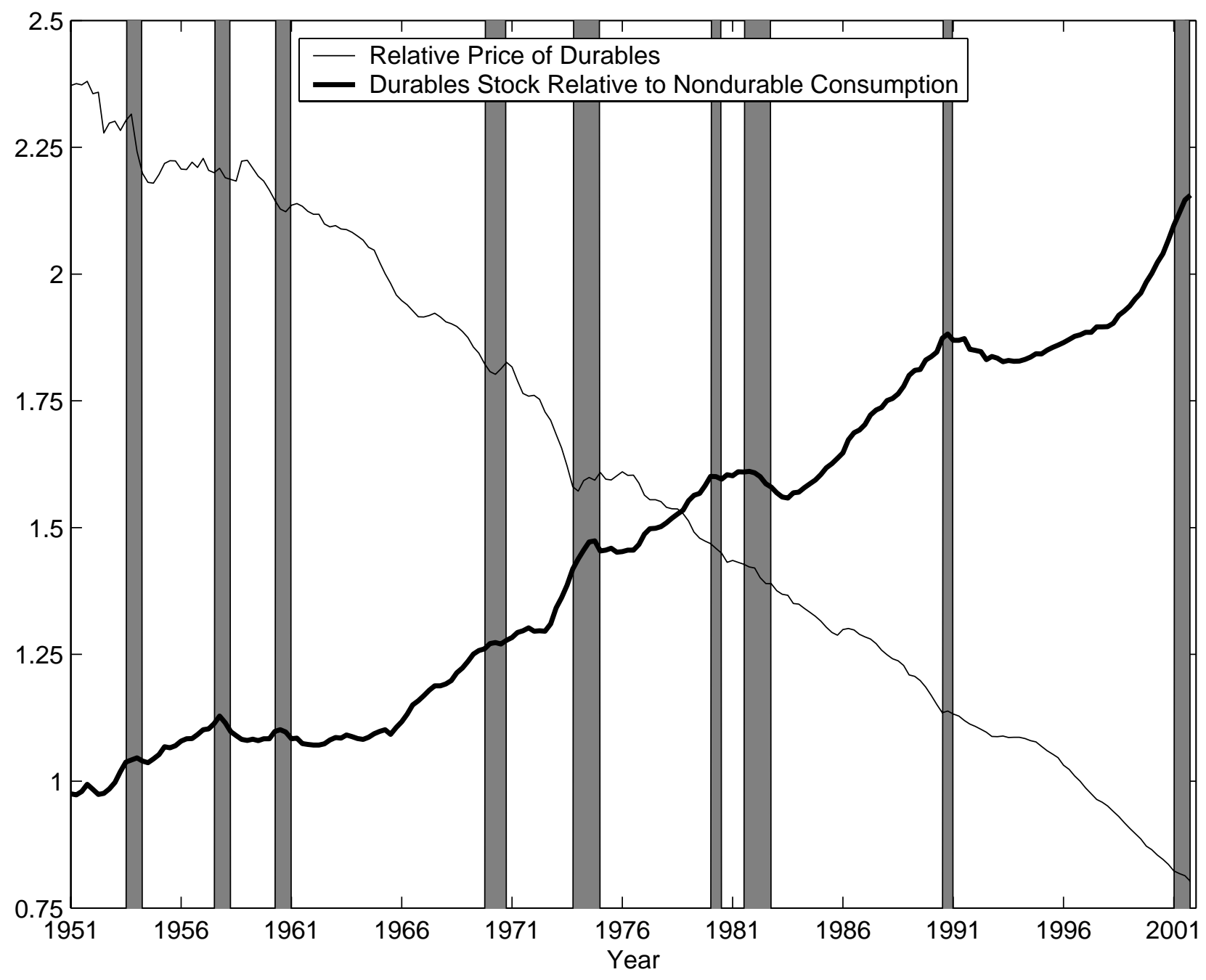

Figure 2: Price and Stock of Durables Relative to Nondurables. The figure is a time series plot of (1) the price of durables as a ratio of the price of nondurables and (2) the real stock of durables as a ratio of real nondurable consumption. The sample period is 1951:1-2001:4, and the shaded regions are NBER recessions. 
(a) Nondurable Consumption and Durables Stock Growth

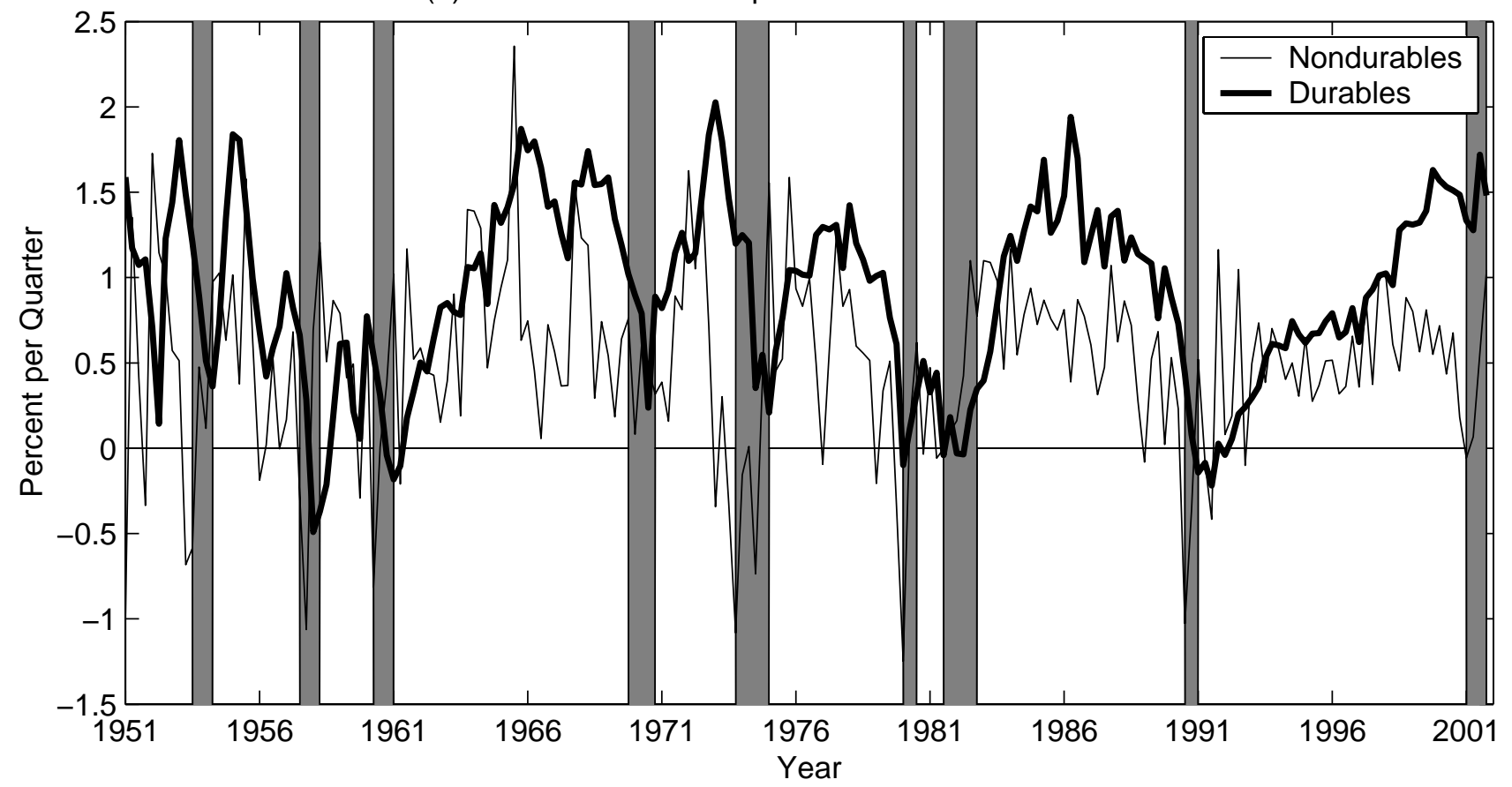

(b) Nondurable Consumption Growth Minus Durables Stock Growth

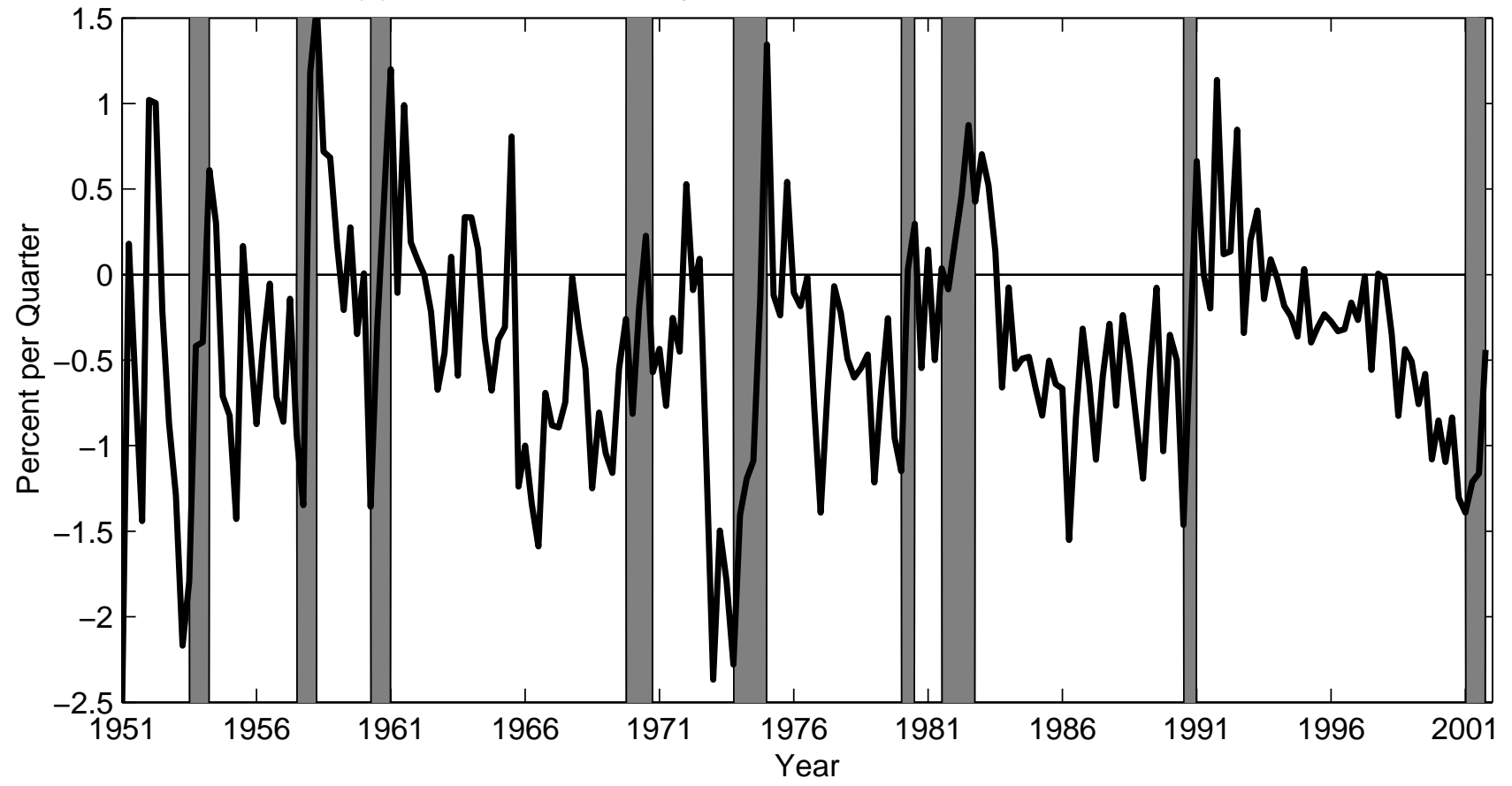

Figure 3: Nondurable and Durable Consumption Growth. The figure is a time series plot of (a) the real growth rates of nondurable consumption and the stock of durables and (b) the difference in the growth rates. See notes to Figure 2. 
(a) Nondurable Consumption Growth

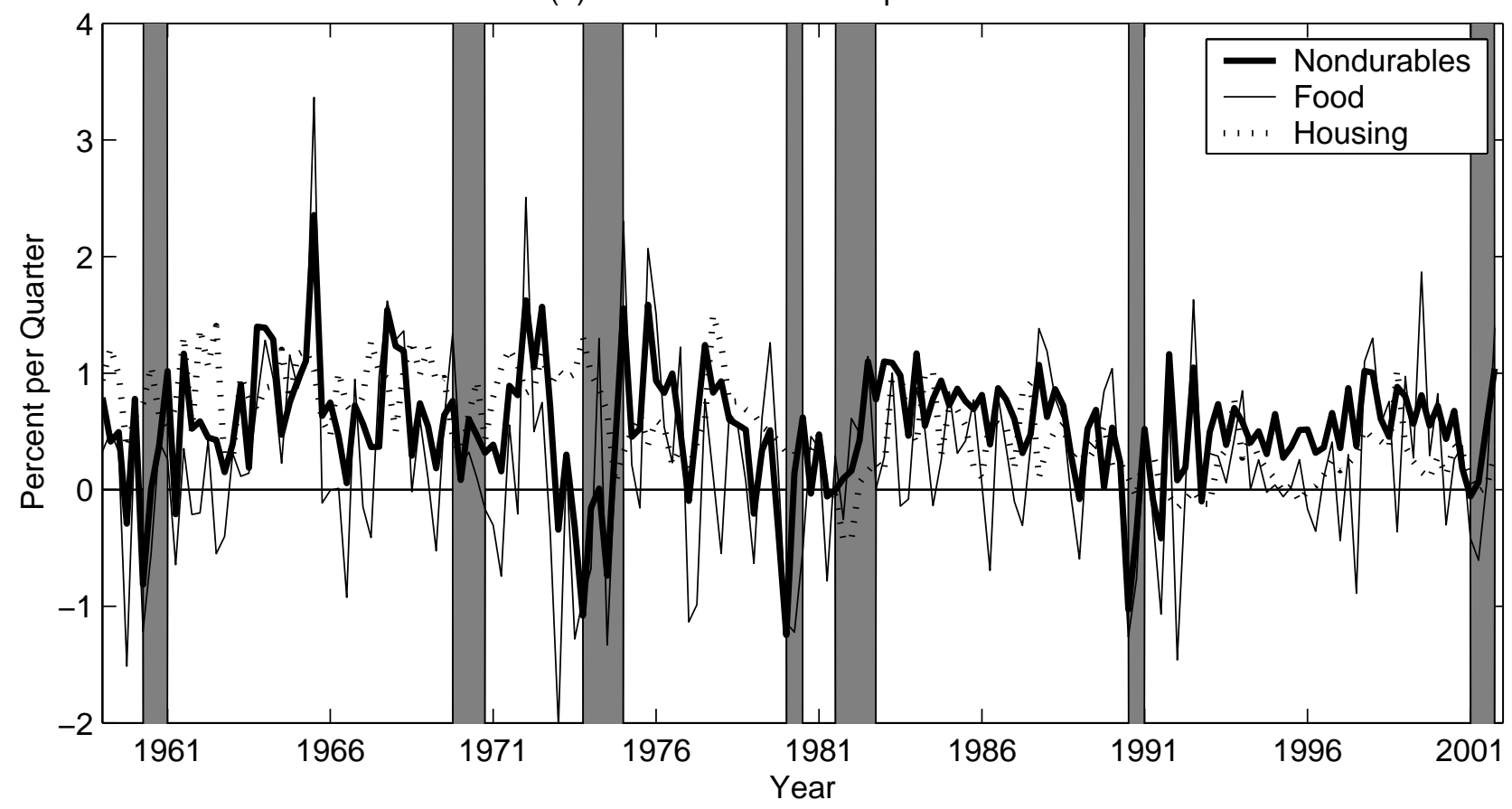

(b) Durables Stock Growth

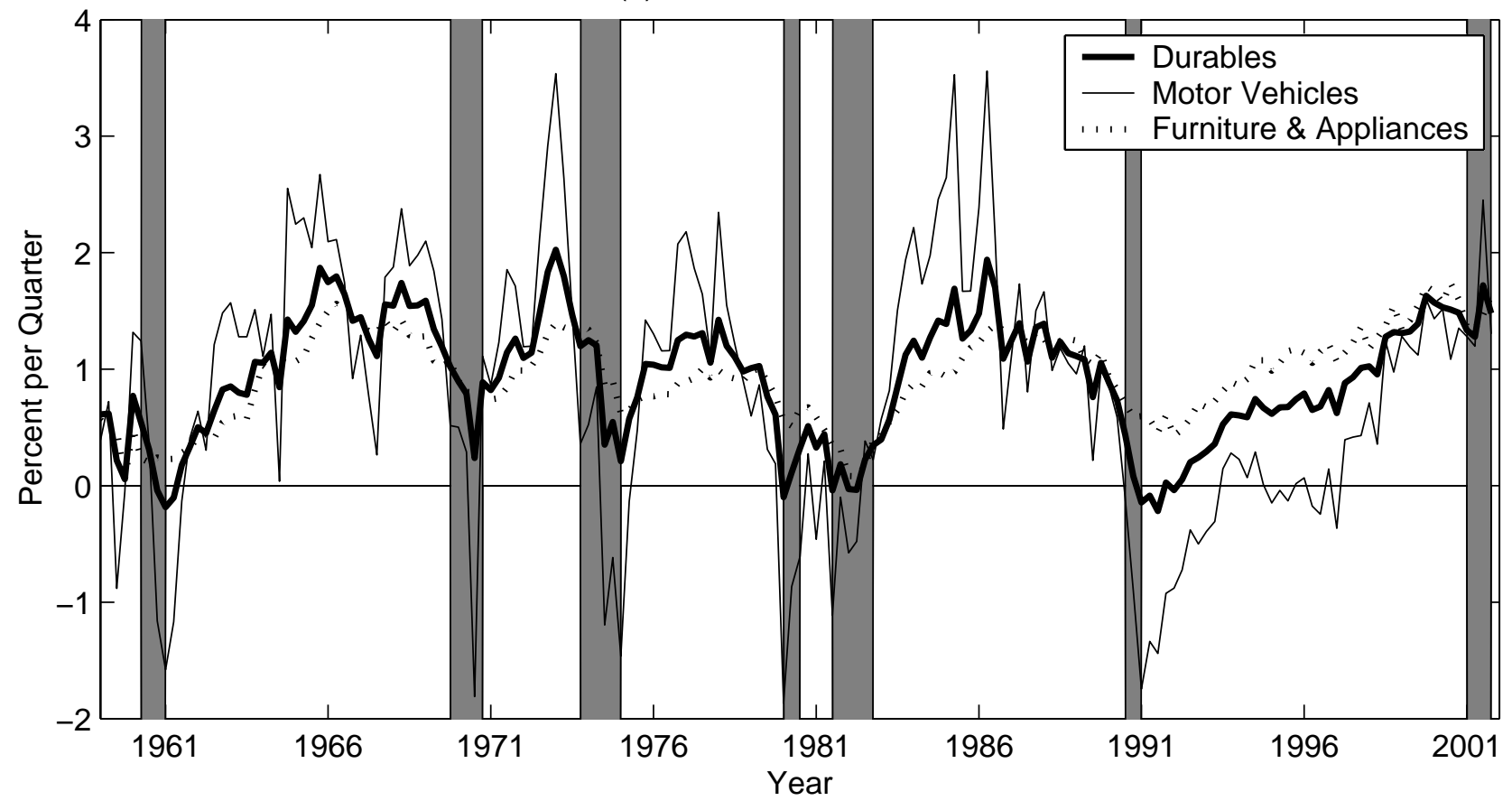

Figure 4: Components of Nondurable and Durable Consumption Growth. The figure is a time series plot of (a) the real growth rates of nondurable, food, and housing consumption and (b) the real growth rates of the stock of durables, motor vehicles, and furniture and appliances. The sample period is 1959:1-2001:4, and the shaded regions are NBER recessions. 
(a) CAPM

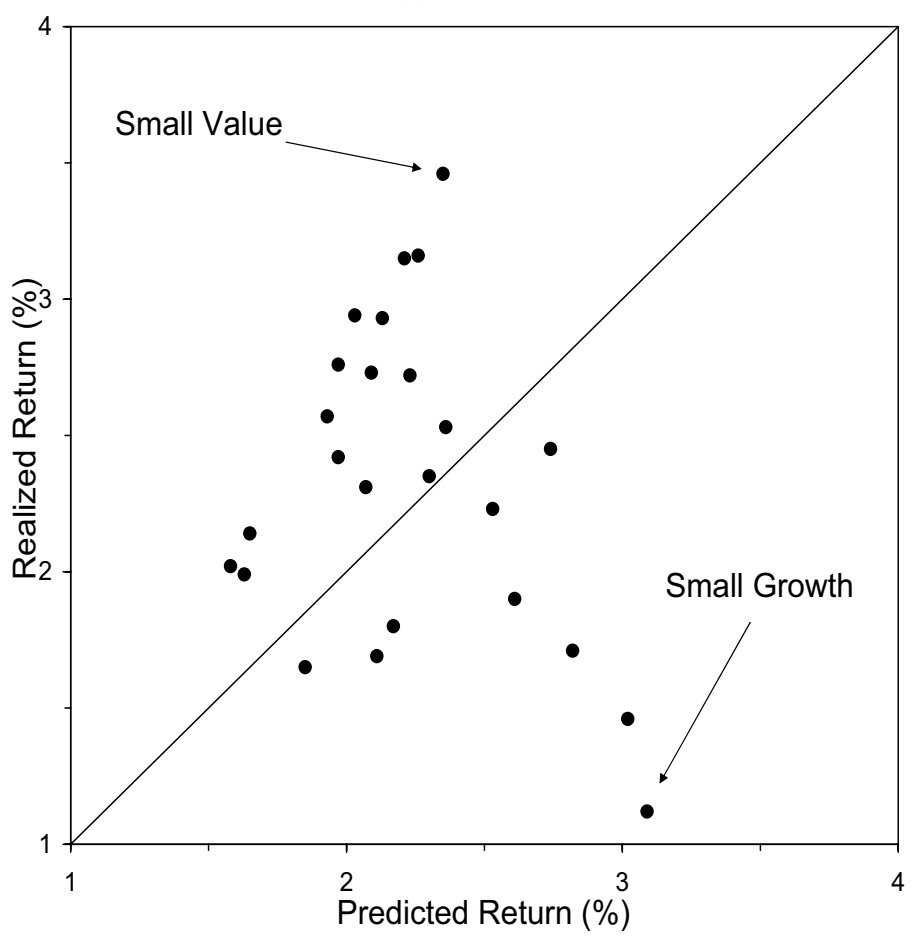

(c) CCAPM

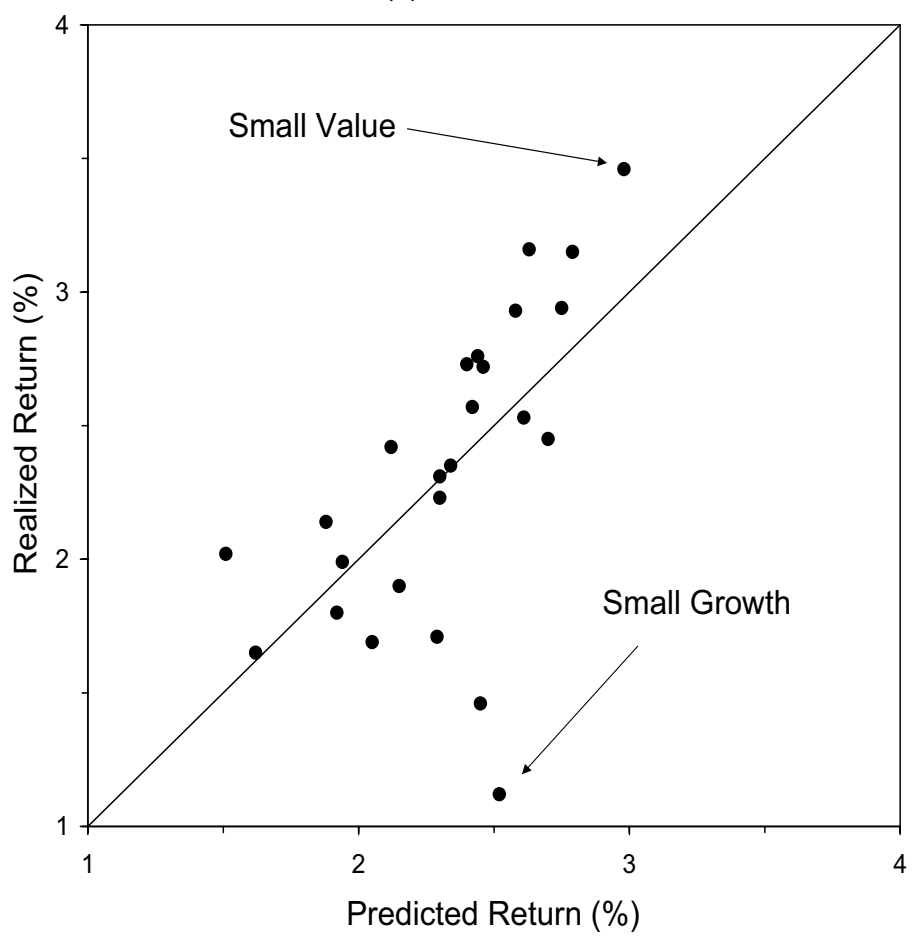

(b) Fama-French

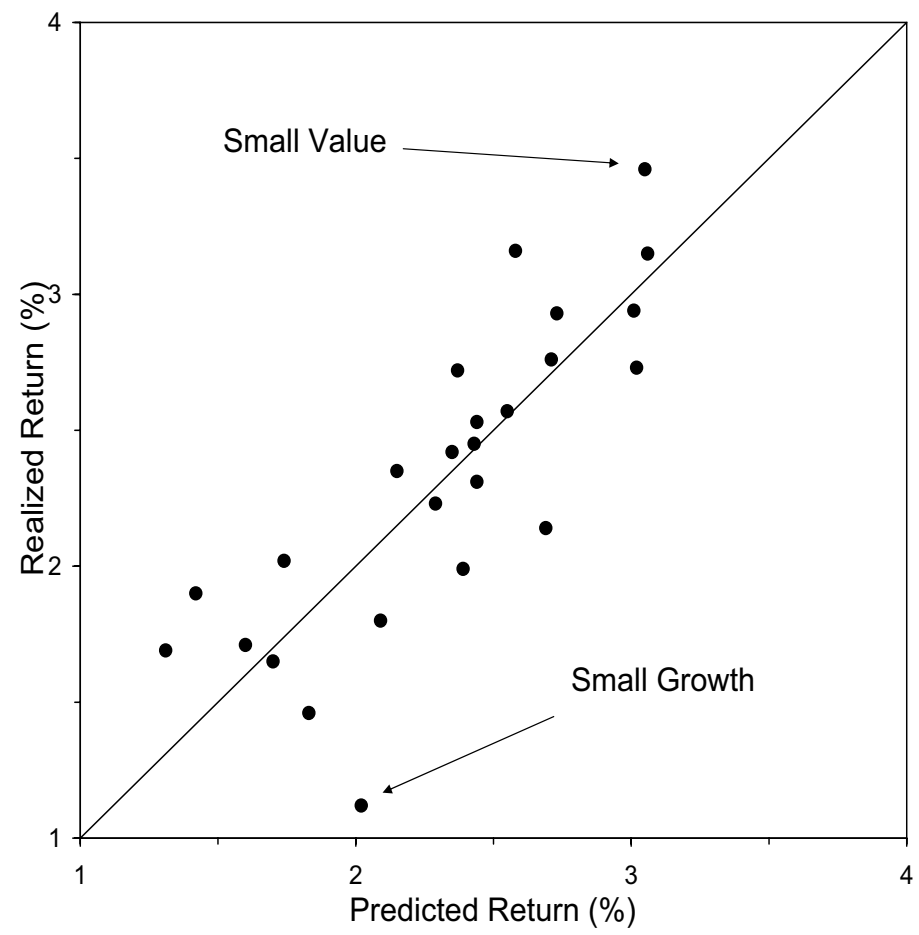

(d) Durable Consumption

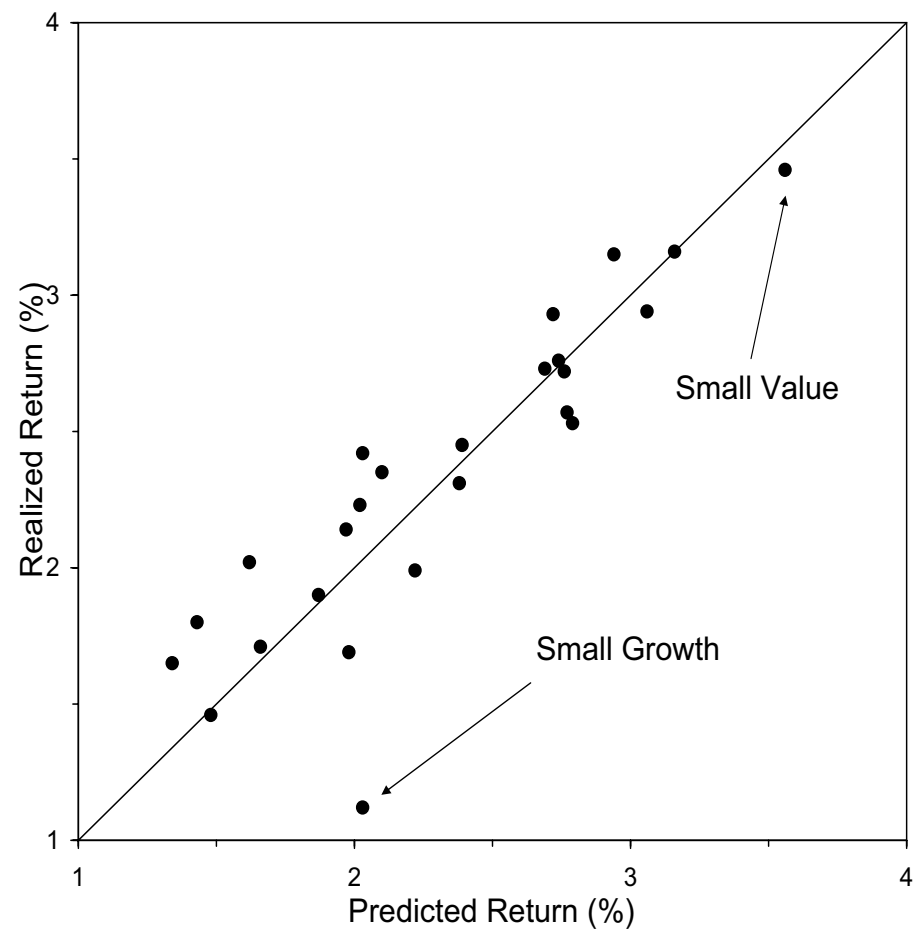

Figure 5: Realized vs. Predicted Returns for the Fama-French Portfolios. The figure plots realized versus predicted excess returns (per quarter) for the 25 Fama-French portfolios sorted by size and book-to-market equity. The estimated models are (a) the CAPM, (b) the Fama-French three-factor model, (c) the CCAPM, and (d) the durable consumption model. 


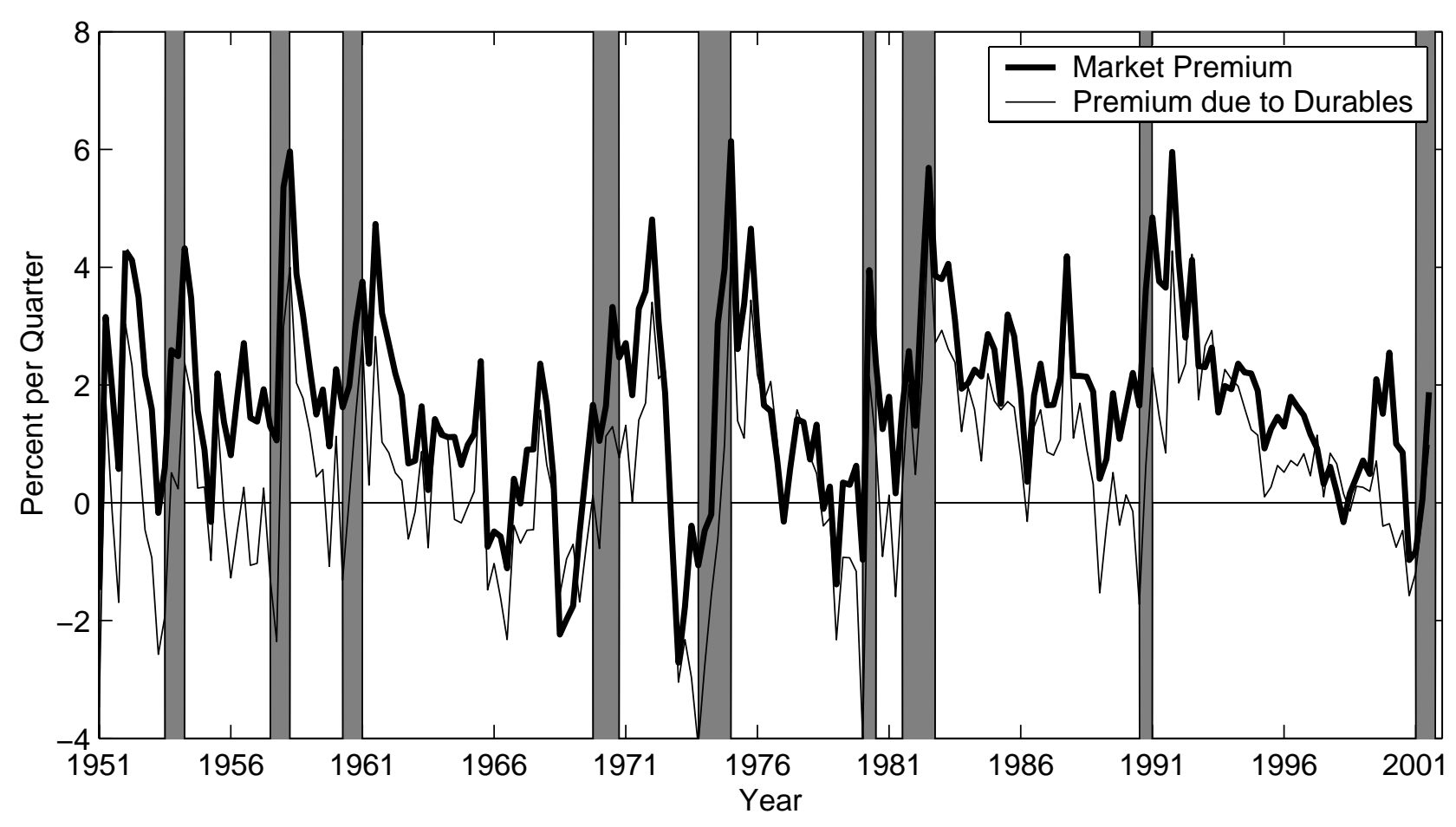

Figure 6: Time Variation in the Market Premium. The figure is a time series plot of expected excess returns on the CRSP value-weighted portfolio. The sample period is 1951:1-2001:3, and the shaded regions are NBER recessions. 
(a) EIS Inverse of Risk Aversion

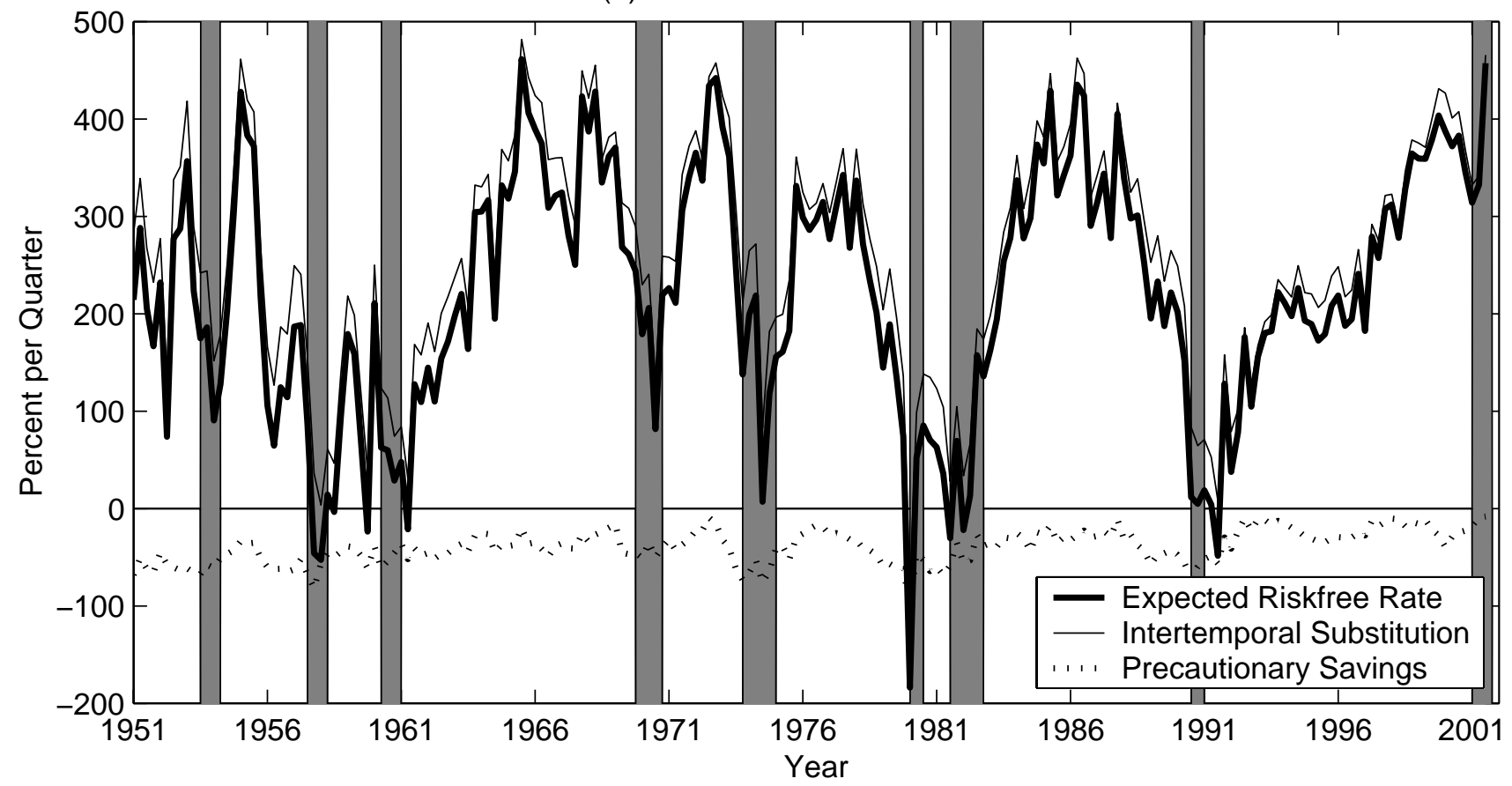

(b) EIS Unrestricted

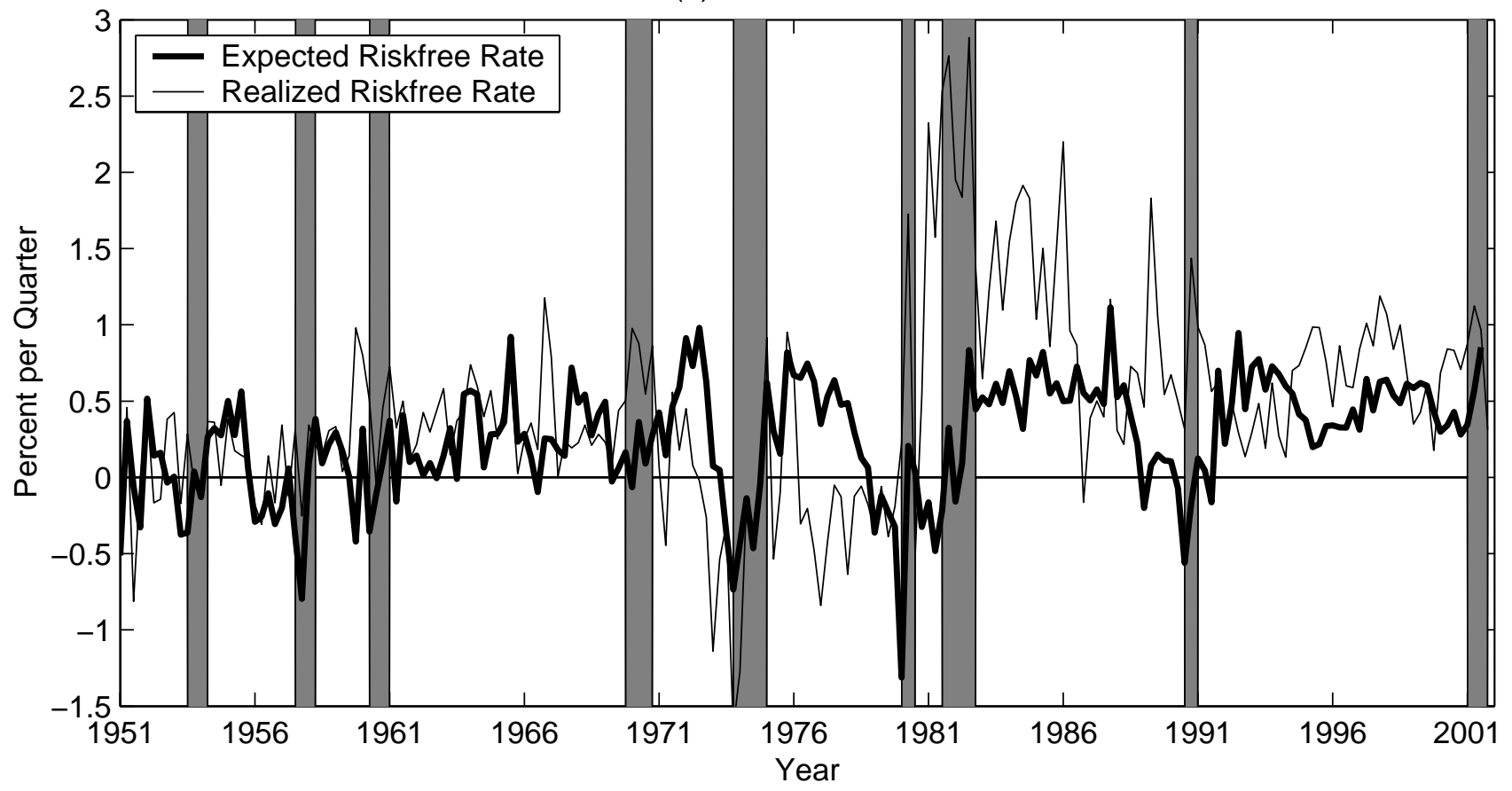

Figure 7: Expected Riskfree Rate. The figure is a time series plot of the expected riskfree rate implied by the durable consumption model when (a) the EIS is restricted to be the inverse of risk aversion and (b) the EIS is unrestricted. See notes to Figure 6. 